\title{
Killing of Staphylococcus aureus in murine macrophages by chloroquine used alone and in combination with ciprofloxacin or azithromycin
}

This article was published in the following Dove Press journal:

Journal of Inflammation Research

22 January 2015

Number of times this article has been viewed

\section{Somrita Dey \\ Biswadev Bishayi \\ Department of Physiology, Immunology Laboratory, University of Calcutta, University Colleges of Science and Technology, Calcutta, India}

Correspondence: Biswadev Bishayi Department of Physiology, Immunology Laboratory, University of Calcutta, University Colleges of Science and Technology, 92 APC Road,

Calcutta 700009, West Bengal, India

$\mathrm{Tel}+9 \mid 3323508386$ ext 225

$\mathrm{Fax}+9 \mid 3323519755$

Email biswa_dev2@yahoo.com

\begin{abstract}
This study aimed to determine any alteration in the killing of Staphylococcus aureus in murine peritoneal macrophages when chloroquine (CQ) is used alone compared with when it is used in combination with ciprofloxacin (CIP) or azithromycin (AZM). The study also aimed to find out the implication of reactive oxygen species (ROS) production and cytokine release in the intracellular killing of $S$. aureus in macrophages. We present here data obtained with a model of $S$. aureus-infected mouse peritoneal macrophages in which the intracellular growth of the bacteria and the influence of antibiotics was monitored for 30, 60, and 90 minutes in the presence or absence of CQ along with the production of ROS and alteration in levels of antioxidant enzymes and cytokines. It was observed that $S$. aureus-triggered cytokine response was regulated when macrophages were co-cultured with CQ and AZM as compared with CQ stimulation only. It can be suggested that action of AZM in mediating bacterial killing is enhanced by the presence of CQ, indicating enhanced uptake of AZM during early infection that may be essential for bacteria killing by AZM. Reduction of oxidative stress burden on the S. aureusinfected macrophages may pave the way for better killing of internalized $S$. aureus by CQ plus ciprofloxacin (CIP) or CQ plus AZM. Based on these observations, one may speculate that in an inflammatory milieu, CQ loaded with AZM elicits a stronger proinflammatory response by increasing the intracellular uptake of AZM or CIP, thus enabling the immune system to mount a more robust and prolonged response against intracellular pathogens.
\end{abstract}

Keywords: azithromycin, ciprofloxacin, intracellular survival

\section{Introduction}

Staphylococcus aureus is a major human pathogen causing significant morbidity and mortality in both community- and hospital-acquired infections. ${ }^{1} S$. aureus, which often causes chronic or relapsing disease, has been reported to persist as an opportunistic intracellular organism both in vitro and in vivo. ${ }^{2} S$. aureus, commonly known as an extracellular host pathogen, even stimulates the inflammatory response and thus undergoes an intracellular phase within professional phagocytes, which encompass cells of the monocytic/macrophage lineage. ${ }^{3}$ An effective treatment for the infections caused by intracellular bacterial forms can only be achieved using an antibiotic that can concentrate sufficiently at the site of microbial residence and further maintain activity in the intracellular environment. ${ }^{4,5}$ However, it has been observed that many microbial pathogens are protected, inside the cell, from antibiotics to which they are susceptible in vitro. ${ }^{6,7} S$. aureus has been reported to express a wide array of secreted and cellsurface-associated virulence factors to help evade immune responses. ${ }^{8}$ The treatment of $S$. aureus infections has been increasingly problematic due to the high prevalence of 
multi-antibiotic-resistant strains, such as methicillin-resistant S. aureus, ${ }^{9}$ and the emergence of vancomycin-resistant S. aureus strains. ${ }^{10}$

$S$. aureus has been reported to survive within phagocytic cells both in polymorphonuclear neutrophils (PMN) and monocytes. ${ }^{11}$ However, recent experiments assessing invasion and the intracellular survival of $S$. aureus in endothelial and epithelial cells, and macrophages and osteoblasts ${ }^{12-19}$ have suggested that such events may contribute to the persistence of $S$. aureus during infections such as septic arthritis. $^{20-22}$ Moreover, it has long been known that professional phagocytes may serve as intracellular reservoirs of $S$. aureus. ${ }^{23}$ In order to survive and induce infection, pathogenic bacteria have to cope with their changing environment, as well as continuous attacks by the host's antimicrobial defense system.

$S$. aureus may become intracellular, at least within monocytes, macrophages, and PMN, when host defense mechanisms are activated. ${ }^{24}$ The facultative intracellular persistence of staphylococci may play an important role in the pathogenesis, because this localization protects them from both humoral and cell-mediated immune responses. The intracellular habitat of $S$. aureus calls for antibiotics with intracellular activity toward $S$. aureus. However, antibiotics have routinely been tested only for their in vitro activity on extracellular bacteria. Obviously, the intracellular activity of antibiotics can significantly differ from that exerted extracellularly. In general it seems impossible to deduce the intracellular antibacterial activity of antibiotics from standard susceptibility tests. ${ }^{25}$ Moreover, it has been reported that approximately one-third of clinical $S$. aureus isolates not only survived in but also killed their eukaryotic host cells, and this was accompanied by increased in vivo virulence. ${ }^{26}$ Therefore, a successful anti-staphylococcal therapy should include the elimination of intracellular bacteria and the rescue of host cells from staphylococci-induced cell death.

Earlier studies on the intracellular accumulation and activity of ciprofloxacin (CIP) and levofloxacin using different cellular models of $S$. aureus-infected phagocytes have also reported a bacteriostatic rather than a bactericidal effect of fluoroquinolones. ${ }^{27-29}$ Indeed, to become active, the intracellular portion of the antibiotic must come into direct contact with $S$. aureus, which resides mainly in the phagolysosomes of phagocytic cells. Fluoroquinolones are able to diffuse in various subcellular compartments. ${ }^{30}$ In particular, macrolides have potential "nonantibiotic" anti-inflammatory activity. ${ }^{31}$ Macrolides strongly accumulate within phagocytes (the necessary basis of their intracellular bioactivity), and this cellular concentration can modify phagocytic cell activities. ${ }^{32}$ In addition, the phagolysosomal environment is apt to inactivate fluoroquinolones. Indeed, phagolysosomes are characterized by a low $\mathrm{pH}(4.8-5.0)^{33}$ and fluoroquinolones, including levofloxacin, are known to have a reduced activity in acidic media ${ }^{34}$ in comparison to macrolides such as azithromycin (AZM).

In the study reported here, AZM, a macrolide, was essentially chosen because, bacteriostatic and time-dependent antibiotics accumulate in cells to a large extent, and are largely localized in acidic vacuoles. ${ }^{38,39} \mathrm{CIP}$, an example of a fluoroquinolone, was chosen because it shows a marked concentration-dependent bactericidal effect but accumulates quickly in cells and distributes in the cytosol. ${ }^{40,41}$

It has been reported that acid $\mathrm{pH}$ conditions markedly decrease macrolides' activity - for example, the alkalinization of phagolysosomes markedly increases the intracellular activity of amikacin. ${ }^{42}$ The activity of fluoroquinolones is, however, less affected by acid $\mathrm{pH} .{ }^{43}$ Although it has been suggested that the alkalinization of phagolysosomes markedly increases the intracellular activity of macrolides. Conditions such as $\mathrm{pH} 5.0$ remarkably reduce the activity of AZM, whereas $\mathrm{pH} 7.3$ restores its activity. ${ }^{43}$ After chloroquine (CQ) treatment, $\mathrm{pH}$ quantification in the phagosome was not done, but there are reports supporting our hypothesis in relation to the concentration of $\mathrm{CQ}$ and time of incubation used in our study. In one study, ${ }^{44}$ the treatment of human macrophages with $100 \mu \mathrm{M}$ CQ raised the $\mathrm{pH}$ of Cryptococcus neoformans-laden phagosomes to 7.3, whereas the activity of CIP was less affected by $\mathrm{pH}$. However, as far as we are aware, the macrophage response after $S$. aureus infection, especially in relation to ROS production and cytokine release by phagocytes during CIP or AZM treatment in alkalinized intra-lysosomal $\mathrm{pH}$, has not yet been studied.

$\mathrm{CQ}$ is known to have anti-inflammatory effects and has been used in the treatment of various diseases including rheumatoid arthritis, septic shock, and discoid lupus erythematosus. ${ }^{45}$ Some of the effects of CQ in these diseases appear through interfering with the cytokine responses of the host. ${ }^{46} \mathrm{CQ}$ is known to inhibit several functions of macrophages, ${ }^{47}$ but its effect on macrophages production of ROS after $S$. aureus infection and its possible implication in the intracellular survival of $S$. aureus have not yet been reported as far as we are aware.

It has been seen that CQ administration attenuates the production of typical serum pro- and anti-inflammatory cytokines such as tumor necrosis factor alpha (TNF- $\alpha$ ) and interleukin (IL)-10. ${ }^{48}$ Moreover, it was confirmed that CQ 
exerts some anti-inflammatory effects through the downregulation of TNF- $\alpha$ production and signaling in macrophages, as well as cytokine pattern production. ${ }^{49}$ Cooper and Magwere reported that the lysosomotropic effects of CQ are widely responsible for its anti-inflammatory properties that a decrease in the production of proinflammatory cytokines such as interferon gamma (IFN- $\gamma$, TNF- $\alpha$, IL-1, and IL-6), and also emphasized the importance of non-lysosomotropic mechanisms (it was shown that CQ could inhibit TNF- $\alpha$ release in macrophages through inhibition of TNF- $\alpha$ messenger RNA synthesis). ${ }^{50}$

This study was attempted to determine whether there is any alteration in the killing of $S$. aureus in murine peritoneal macrophages when CQ is used alone compared with when it is used in combination with CIP or AZM. We also wanted to find out the implication of ROS production and cytokine release in the intracellular killing of $S$. aureus in macrophages. We present here data obtained from a model of S. aureus-infected mouse peritoneal macrophages in which the intracellular growth of the bacteria and the influence of antibiotics were monitored for 30,60, and 90 minutes in the presence or absence of CQ. Murine peritoneal macrophages were selected because they are quite permissive toward a variety of intracellular infectious agents, allowing detailed analysis of the effects of antibiotics without too much interference from the host-derived mechanisms of defense. We selected commonly used antibiotics (CIP and AZM) on the basis of their uptake by macrophages and their intracellular activity during alkalinization of phagosomes. In fact, we noted that the $S$. aureus-triggered cytokine response was regulated when macrophages were co-cultured with $\mathrm{CQ}$ and AZM as compared with CQ stimulation only. Based on these observations, one may speculate that, in an inflammatory milieu, CQ loaded with AZM elicits a stronger proinflammatory response in neighboring macrophages than AZM alone, thus enabling the immune system to mount a more robust and prolonged response against intracellular pathogens.

\section{Materials and methods Maintenance of animals and cells}

All experiments involving animals were conducted according to the protocols that had been approved by the Institutional Animal Ethics Committee (IAEC) of the Department of Physiology, University of Calcutta, under the guidance of the Indian Ministry of Environment and Forest's Committee for the Purpose of Control and Supervision of Experiments on Animals (approval number: 820/04/ac/CPCSEA, dated September 5, 2013). Wild-type male Swiss albino mice were used throughout the study. To minimize the feeling of hypoxia or discomfort before and during dissection and tissue collection, mice were anaesthetized with an inhaled anesthetic (ether) before terminal surgery. Euthanasia was performed by general anesthesia followed by vital tissue removal using 2\%-3\% ether for induction and $1 \%$ for maintenance. Macrophages were prepared from the peritoneal fluids of thioglycolate-administered mice.

\section{Preparation of bacteria for in vitro infection of peritoneal macrophages}

The S. aureus strain AG-789, which was found to be methicillin resistant and catalase positive, was obtained from Apollo Gleneagles Hospital, Calcutta, West Bengal, India. The S. aureus strain (AG-789) was grown overnight in Luria Bertani broth (HiMedia Laboratories, Mumbai, India), diluted with fresh broth then cultured until the mid-logarithmic phase of growth. Bacteria were harvested, washed twice with sterile saline, and adjusted to the desired inoculums spectrophotometrically before infection (optical density $[\mathrm{OD}]_{620}=0.2$ for $5.0 \times 10^{7}$ cells $/ \mathrm{mL}$ for $S$. aureus) and the number of colonyforming units (CFU) in the desired inoculums was confirmed by serial dilution and culture on blood agar. ${ }^{20-22}$

\section{Isolation and stimulation of peritoneal macrophages}

The mice, aged 6-8 weeks and fed standard laboratory chow and water, were injected intraperitoneally with $2 \mathrm{~mL}$ of $4 \%$ sterile thioglycolate broth, and the resulting peritoneal exudates were harvested by lavage of the peritoneal cavities with endotoxin-free Hank's solution 4-5 days later. Peritoneal macrophages were suspended in $0.83 \%$ ammonium chloride solution containing $10 \%(\mathrm{v} / \mathrm{v})$ Tris buffer ( $\mathrm{pH} 7.65)$ to lyse erythrocytes. The cells were resuspended in Roswell Park Memorial Institute (RPMI) 1640 medium supplemented with $10 \%$ fetal bovine serum (FBS), $100 \mathrm{IU} / \mathrm{mL}$ penicillin, and $100 \mu \mathrm{g} / \mathrm{mL}$ streptomycin. Cells were then kept in plastic petri dishes for their adherence to the surface of the plastic petri dishes. Non-adherent cells were removed by aspiration and washing with RPMI 1640 medium before the addition of $S$. aureus. The adherent macrophages, more than $95 \%$ of which appeared to be typical macrophages by light microscopy, were used for each experiment. ${ }^{15-17}$ The peritoneal macrophages so collected were suspended in Hank's Balanced Salt Solution (HBSS). Murine peritoneal macrophages $\left(5 \times 10^{6}\right.$ cells $\left./ \mathrm{mL}\right)$ were infected with $S$. aureus $\left(5 \times 10^{6} \mathrm{CFU} / \mathrm{mL}\right)$ for 30,60 , and 90 minutes at $37^{\circ} \mathrm{C}$, in a humidified, $5 \% \mathrm{CO}_{2}$ Heal Force $\mathrm{HF} 151 \mathrm{CO}_{2}$ Incubator 
(Shanghai, People's Republic of China) in the presence or absence of antibiotics and CQ at a dose of $5 \mu \mathrm{g} / \mathrm{mL}^{34}$ either alone or in combination with AZM or CIP at a dose of four times the minimum inhibitory concentration (MIC) for the S. aureus strain (AG-789).

\section{Assay for intracellular killing}

The presence of a large number of $S$. aureus bacteria in some cells that had undergone in vitro culture observed in the bacterial plate count suggests that the bacteria grow intracellularly. In addition, it has been reported that $S$. aureus multiplies in the presence of intact macrophages in cell cultures and would not grow in macrophage-conditioned media. ${ }^{15-17}$ Therefore, the number of $S$. aureus bacteria grown in a petri dish after time-dependent phagocytosis indicates the number of $S$. aureus bacteria that have survived inside the macrophages after ingestion.

For this, murine peritoneal macrophages $\left(5 \times 10^{6} \mathrm{cell} / \mathrm{sL}\right)$ were mixed with $S$. aureus $\left(5 \times 10^{6} \mathrm{CFU} / \mathrm{mL}\right)$ in a cell to bacterium ratio of 1:1 $1^{15-17}$ in RPMI-FBS (5\%) and incubated at $37^{\circ} \mathrm{C}$ in a cell-culture incubator for different times in the presence and absence of antibiotics and CQ either alone or in combination. After centrifugation, cell-culture supernatants were collected and stored for further assay at $-70^{\circ} \mathrm{C}$. Phagocytosis was stopped by adding cold $\left(4^{\circ} \mathrm{C}\right) \mathrm{RPMI}$ 1640 and extracellular $S$. aureus were removed by washing the suspension in RPMI 1640. The pellets were disrupted in sterile water containing $0.01 \%$ bovine serum albumin (BSA) by vigorously vortexing to release the intracellular bacteria in the lysates. The lysates containing bacteria were plated at serial dilutions on mannitol agar plates. The plates were incubated at $37^{\circ} \mathrm{C}$ for a day or two and the number of colonies was determined.

\section{Hydrogen-peroxide production}

Activation of leukocytes by inflammatory stimuli results in the local release of ROS and induces hydrogen-peroxide $\left(\mathrm{H}_{2} \mathrm{O}_{2}\right)$ production. Studies in animals support a critical role for phagocyte oxidative burst in controlling $S$. aureus infection. ${ }^{35-37}$ Therefore, the quantification of $\mathrm{H}_{2} \mathrm{O}_{2}$ in this experimental setup was quite relevant.

So, after time-dependent phagocytosis, supernatants were collected and cell lysates were prepared from the pellet. $\mathrm{H}_{2} \mathrm{O}_{2}$ assay of the supernatants and lysates was performed according to the an earlier described method, with slight modification. ${ }^{51}$ Briefly, $70 \mu \mathrm{L}$ of supernatant or lysate, $20 \mu \mathrm{L}$ horseradish peroxidase $(500 \mu \mathrm{g} / \mathrm{mL}), 70 \mu \mathrm{L}$ of phenol red $(500 \mu \mathrm{g} / \mathrm{mL})$, and $40 \mu \mathrm{L}$ medium were added to each well of the microtiter plates and allowed to incubate for 2 hours at $37^{\circ} \mathrm{C}$. The reaction was stopped by adding $25 \mu \mathrm{L}$ of $2 \mathrm{~N}$ sodium hydroxide $(\mathrm{NaOH})$ and the absorbance reading was taken at $620 \mathrm{~nm}$. The control set received $40 \mu \mathrm{L}$ of HBSS in place of the supernatant/lysate. A standard $\mathrm{H}_{2} \mathrm{O}_{2}$ curve was plotted and the $\mathrm{H}_{2} \mathrm{O}_{2}$ release from the supernatants and lysates evaluated and expressed in terms of $\mu \mathrm{M} / 10^{6}$ cells.

\section{Assay for determination of superoxide anion}

Because intracellular killing is dependent on oxidants, it was expected that superoxide anion production also contributes to $S$. aureus oxidant-dependent killing mechanisms. Since superoxide anion production has been implicated in many physiological and pathological processes, including host innate immune and inflammatory responses to pathogens, we were also interested in determining the amount of superoxide anion released in our experimental setup.

Superoxide anion release assay measures the change in color of cytochrome $\mathrm{C}(\mathrm{cytC})$, when reduced by $\mathrm{O}_{2}{ }^{-}$released from the stimulated macrophages. Cell-free supernatants recovered from $S$. aureus-stimulated macrophages in the presence or absence of antibiotics and CQ alone or in combination were incubated in the presence of cytochrome $\mathrm{C}$ $(100 \mu \mathrm{L}$ at $2 \mathrm{mg} / \mathrm{mL}$ in HBSS). The reaction was terminated by placing the tubes in ice for 5 minutes. The production of superoxide anion was monitored spectrophotometrically using a UV-1800 UV-VIS (ultraviolet-visible) spectrophotometer (Shimadzu Corporation, Tokyo, Japan) at $550 \mathrm{~nm}$ in reference to the blank. Based on the extinction coefficient of (reduced-oxidized CytC), OD $=21 \times 10^{3} \mathrm{M}^{-1} \mathrm{~cm}^{-1}$ and because the vertical light path passing through $100 \mu \mathrm{L} \mathrm{CytC}$ was $3 \mathrm{~mm}$, the absorbance value could be converted to nmol of superoxide anion based on the following formula: nmol of superoxide anion $=($ mean absorbance at $550 \mathrm{~nm} \times 15.87) .{ }^{52}$

\section{Assay for quantification of nitric-oxide production}

Nitric-oxide (NO) release was determined by Griess assay. Thioglycolate-elicited mouse peritoneal macrophages in serum-free RPMI 1640 medium were mixed with $S$. aureus and the mixture was incubated in the presence or absence of the anti-toll-like receptor (TLR)-2 antibody for different times at $37^{\circ} \mathrm{C}$ with $5 \% \mathrm{CO}_{2}$ before being centrifuged. Supernatant or lysate $(50 \mu \mathrm{L})$ was incubated separately in $40 \mu \mathrm{M}$ Tris (pH 7.9) containing $40 \mu \mathrm{M}$ of the reduced form of b-nicotinamide adenine dinucleotide phosphate (NADPH), $40 \mu \mathrm{M}$ flavine adenine dinucleotide, and $0.05 \mathrm{U} / \mathrm{mL}$ nitrate 
reductase at $37^{\circ} \mathrm{C}$ for 15 minutes. Reduced samples were incubated with an equal volume of Griess reagent consisting of sulphanilamide $(0.25 \%$ [w/v] $)$ and $N$-1-naphthylethylenediamine $(0.025 \%[\mathrm{w} / \mathrm{v}])$ for 10 minutes. Absorbance was measured at $550 \mathrm{~nm}$ with the UV-1800 UV-VIS spectrophotometer (Shimadzu Corporation). The total nitrate/nitrite concentration was determined by comparison to a reduced sodium nitrate $\left(\mathrm{NaNO}_{3}\right)$ standard curve. ${ }^{53}$

\section{Determination of antioxidant enzyme} activity in supernatants and lysates after time-dependent phagocytosis of S. aureus in the presence or absence of antibiotics and chloroquine alone or in combination Assay of catalase enzyme activity Typically, S. aureus-stimulated leukocytes produce proinflammatory cytokines, which trigger ROS production in the tissues through NADPH oxidase activation. Thus, the level of antioxidant enzymes or their activity displays the intracellular complex mechanisms of the host's defense. Therefore, to determine the activity of these antioxidant enzymes in neutralizing the ROS molecules produced, we estimated the antioxidant enzyme activity in the supernatant or cellfree lysate of macrophages after infection in the presence or absence of CQ or antibiotics. Catalase enzyme activity in the supernatants or cell-free lysates was determined spectrophotometrically by measuring the decrease in $\mathrm{H}_{2} \mathrm{O}_{2}$ concentration at $240 \mathrm{~nm}$. At time $0,10 \mu \mathrm{L}$ of supernatant or cell-free lysate was added separately to $2.89 \mathrm{~mL}$ of potassium phosphate buffer ( $\mathrm{pH}$ 7.4) in a quartz cuvette. To this, $0.1 \mathrm{~mL}$ of $300 \mathrm{mM} \mathrm{H}_{2} \mathrm{O}_{2}$ was added and absorbance was measured at $240 \mathrm{~nm}$ for 5 minutes at 1-minute intervals. Catalase activity was expressed in terms of $\mathrm{mmol} / \mathrm{min} \mathrm{mg}$ protein. $^{20-22}$

\section{Assay of superoxide dismutase enzyme activity}

In addition to blocking phagolysosomal acidification, subsequent treatment of macrophages with antibiotics might regulate intracellular ROS and can also protect bacteria from oxidative stress by modulating bacterial superoxide dismutase (SOD) expression or catalase activity. So estimation of SOD enzyme activity in this experimental setup was deemed helpful to get an idea of ROS level and is being scavenged by antioxidant enzymes.

Supernatant or cell-free lysate $(100 \mu \mathrm{L})$ was mixed separately with $1.5 \mathrm{~mL}$ of a Tris-ethylenediaminetetraacetic acid (EDTA)-hydrochloric acid ( $\mathrm{HCl}$ ) buffer ( $\mathrm{pH} 8.5$ ), then $100 \mu \mathrm{L}$ of $7.2 \mathrm{mmol} / \mathrm{L}$ pyrogallol was added and the reaction mix- ture was incubated at $25^{\circ} \mathrm{C}$ for 10 minutes. The reaction was terminated by the addition of $50 \mu \mathrm{L}$ of $1 \mathrm{M} \mathrm{HCl}$ and measured at $420 \mathrm{~nm}$. One unit was determined to be the amount of enzyme that inhibited the oxidation of pyrogallol by $50 \%$. The activity was expressed as $\mathrm{U} / \mathrm{mg}$ protein. ${ }^{20-22}$

\section{Assay of reduced glutathione content}

SOD, catalase, and glutathione (GSH) enzymes are important scavengers of the superoxide anion and hydrogen peroxide. These enzymes prevent the generation of the hydroxyl radical and protect the cellular constituents from oxidative damage. SOD rapidly dismutates superoxide anion to $\mathrm{H}_{2} \mathrm{O}_{2}$, which is further degraded by catalase into water and oxygen. It was demonstrated that a decrease in the concentration of cellular GSH indicates oxidative damage due to stress or inflammation. ${ }^{54}$ So estimation of GSH level was also rational in this setup.

Reduced GSH content (as acid-soluble sulfhydryl) was estimated by its reaction with 5,5'-dithiobis-(2-nitrobenzoic acid) (DTNB; Ellman's reagent) following the method of Sedlak and Lindsay with some modifications. ${ }^{55}$ An amount of the sample $(0.3 \mathrm{~mL})$ was mixed with $0.3 \mathrm{~mL} 10 \%$ trichloroacetic acid (TCA) followed by vortexing. Then the mixture was centrifuged at $5,000 \mathrm{rpm}$ for 10 minutes at $4^{\circ} \mathrm{C}$. To $250 \mu \mathrm{L}$ of the resultant mixture, supernatant was added along with $500 \mu \mathrm{L} 0.8 \mathrm{M}$ Tris- $\mathrm{HCl}$ followed by addition of $25 \mu \mathrm{L}$ DTNB. The absorbance was measured at $412 \mathrm{~nm}$ using a UV-VIS spectrophotometer to determine GSH content. The values were expressed as nmol of GSH per mg protein.

\section{Determination of lipid peroxidation level}

Lipid peroxidation (LPO) of both the supernatants and lysates were determined as thiobarbituric acid (TBA)-reactive substances. In brief, the supernatant or lysate was mixed with TCA-TBA-HCl reagent, mixed thoroughly, and heated for 20 minutes at $80^{\circ} \mathrm{C}$. The tubes containing the samples were then cooled to room temperature. The absorbance of the pink chromogen present in the clear supernatant after centrifugation at $1,200 \times g$ for 10 minutes at room temperature was measured at $532 \mathrm{~nm}$ using a UV-VIS spectrophotometer. Tetraethoxypropane was used as the standard. The values were expressed as nmol of TBA-reactive substances per mg protein. ${ }^{20}$

\section{Assay of bactericidal enzyme (lysozyme) activity}

Through lysosomal degradation and response to secondary ligands, macrophages are able to extend and maximize 
the inflammatory response. The importance of lysosomal degradation and bactericidal enzymes like lysozymes in the immune response is supported by numerous studies. Pathogens evolving to inhibit lysosomal fusion, acidification, and lysosomal enzymes are necessary to release additional ligands and enhance innate signaling. Therefore, the estimation of lysozyme enzyme activity in this study was quite rational.

The supernatants and cell-free lysates obtained in the phagocytosis assay were used to estimate the lysozyme content after varying phagocytic times. Lysozyme enzyme activity was estimated according to the method described by Colowick et al. ${ }^{56}$ A suspension of Micrococcus lysodeikticus in $0.15 \mathrm{M}$ potassium phosphate buffer ( $\mathrm{pH}$ 6.2) was prepared and its optical density was fixed at $0.6-0.7$ at $450 \mathrm{~nm}$. An amount of this suspension $(900 \mu \mathrm{L})$ was mixed with $50 \mu \mathrm{L}$ of $1 \%$ Triton $^{\mathrm{TM}} \mathrm{X}-100$ and the reaction was started by adding $50 \mu \mathrm{L}$ supernatant or cell-free lysate. The decrease in optical density was recorded at $450 \mathrm{~nm}$ as a function of time. The change in absorbance for the first minute only was used to determine the rate of the reaction. One unit of enzyme was defined as the amount of enzyme that produced a decrease in absorbance of $0.001 / \mathrm{min}$ at $450 \mathrm{~nm}$.

\section{Assay for protein estimation of the sample}

The protein content of the supernatants and lysates was measured by previously described method. ${ }^{57}$

\section{Tumor necrosis factor alpha and interferon gamma enzyme-linked immunosorbent assays}

Murine peritoneal macrophages $\left(5 \times 10^{6}\right.$ cells $\left./ \mathrm{mL}\right)$ were mixed with $S$. aureus $\left(5 \times 10^{6} \mathrm{CFU} / \mathrm{mL}\right)$ in a cell to bacterium ratio of $1: 1^{58,59}$ in RPMI-FBS $(5 \%)$ and incubated at $37^{\circ} \mathrm{C}$ in a cell-culture incubator for various times in the presence and absence of antibiotics and CQ either alone or in combination. After incubation, the cell-culture supernatants were collected and stored at $-70^{\circ} \mathrm{C}$ prior to analysis. Supernatants from different groups were normalized to the protein content by Bradford protein assay before the assay and levels of TNF- $\alpha$ and IFN $\gamma$ were determined. Production was assayed using enzyme-linked immunosorbent assay (ELISA) kits according to the instructions provided by the manufacturer (RayBiotech, Inc., Norcross, GA, USA) in an ELISA reader (Bio-Rad Laboratories Inc., Hercules, CA, USA).

\section{Statistical analysis}

Isolated peritoneal macrophages from mice were pooled together to obtain the requisite amount of macrophages $\left(5 \times 10^{6}\right.$ cells $\left./ \mathrm{mL}\right)$ and the different parameters were measured. This was repeated three times for each parameter (eg, $\mathrm{H}_{2} \mathrm{O}_{2}$ production) then the mean value of the triplicate experiments was taken for calculation. Data were expressed as mean \pm standard deviation. Means were compared between groups using analysis of variance. A $P$-value $<0.05$ was considered significant.

\section{Results}

\section{Effect of chloroquine and antibiotic treatment either alone or in combination on phagocytosis of $S$. aureus by peritoneal macrophages}

Control macrophages were readily able to phagocytose $S$. aureus. After 90 minutes of incubation the number of viable bacteria within macrophages declined. However, the number of bacteria phagocytosed by CQ-treated macrophages appeared to be lower than that observed for macrophages not treated with CQ at the different incubation times. Overall, the experimental results indicate that CQ treatment leads to a reduction in the uptake of $S$. aureus cells by macrophages, presumably by interfering with phagocytosis. CIP and AZM do not affect the viability of macrophages (data not shown), but almost immediately after being applied to infected macrophages inhibits $S$. aureus growth and replication (data not shown).

There were statistically significant differences between the number of viable bacteria recovered from CQ plus antibiotic-treated macrophages before $S$. aureus infection and that from the CQ-pretreated plus $S$. aureus-infected macrophages at 30 and 60 minutes postinfection. However, the number of bacteria surviving intracellularly in the CQ plus AZM-treated macrophages before $S$. aureus infection was greater than that in the CQ plus CIP-treated macrophages before infection at 90 minutes of incubation when compared to CQ-treated S. aureus-infected macrophages (Figure 1).

\section{Effect of chloroquine and antibiotic treatment on S. aureus infection-induced hydrogen-peroxide production in the lysate and supernatant of murine peritoneal macrophages}

The amount of $\mathrm{H}_{2} \mathrm{O}_{2}$ released in the lysate (Figure $2 \mathrm{~A}$ ) or supernatant (Figure 2B) was significantly higher $(P<0.05)$ in $S$. aureus-infected macrophages than in control macrophages at 30, 60, and 90 minutes after $S$. aureus infection. There was a statistically significant increase in the amount of $\mathrm{H}_{2} \mathrm{O}_{2}$ produced $(P<0.05)$ in CQ-pretreated macrophages at 30 and 60 minutes post-incubation in both supernatant and lysate but 


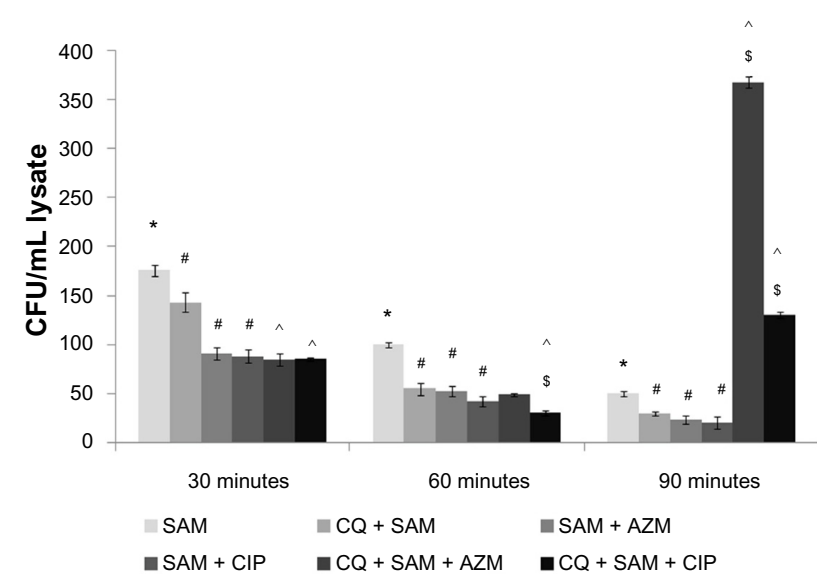

Figure I Effect of chloroquine (CQ) and antibiotic treatment on intracellular killing assay on Staphylococcus aureus-infected murine peritoneal macrophages. Intracellular killing assay was performed on the lysate after time-dependent phagocytosis in the presence or absence of CQ or antibiotics.

Notes: Intracellular killing assay is expressed in terms of the colony-forming units $(\mathrm{CFU}) / \mathrm{mL}$ lysate. Results are presented as mean \pm standard deviation of three independent experiments. *Significant difference with respect to CM; " significant difference with respect to SAM; ^significant difference with respect to chloroquine (CQ) plus $S$. aureus-infected macrophages at the $P<0.05$ level of significance; \$significant difference with respect to either ciprofloxacin (CIP) or azithromycin (AZM) plus S. aureus-infected macrophages.

Abbreviations: CM, control macrophages; $\mathrm{CQ}+\mathrm{SAM}$, chloroquinepretreated + S. aureus-infected macrophages; CQ + SAM + AZM, chloroquinepretreated macrophages infected with $S$. aureus and then treated with azithromycin; $\mathrm{CQ}+\mathrm{SAM}+\mathrm{CIP}$, chloroquine-pretreated macrophages infected with S. aureus and then treated with ciprofloxacin; SAM, S. aureus-infected macrophages; SAM + AZM, S. aureus-infected macrophages treated with azithromycin; SAM + CIP, S. aureusinfected macrophages treated with ciprofloxacin.

there was a decrease at 90 minutes in the supernatant when compared with untreated $S$. aureus-infected macrophages (Figure 2A and B).

Macrophages pretreated either with CIP or AZM alone before $S$. aureus infection also showed increased production of $\mathrm{H}_{2} \mathrm{O}_{2}$ in the lysate in comparison to the amount released by untreated $S$. aureus-infected macrophages. However, administration of either CIP or AZM to CQ-pretreated macrophages before $S$. aureus infection showed reduced $\mathrm{H}_{2} \mathrm{O}_{2}$ release both in the supernatant and lysate when compared with CQ plus S. aureus-infected macrophages (Figure $2 \mathrm{~A}$ and B). The $\mathrm{H}_{2} \mathrm{O}_{2}$ release was also lower in CQ-pretreated macrophages were incubated with CIP or AZM before $S$. aureus infection than in CIP- or AZM-treated $S$. aureus-infected macrophages at 30,60 , and 90 minutes in the cell lysate (Figure 2A).

\section{Effect of CQ and antibiotic treatment on S. aureus infection-induced superoxide anion production in the lysate and supernatant by murine peritoneal macrophages}

The amount of superoxide anion ( $\mathrm{nmol} / 10^{6}$ cells) released in the supernatant and lysates was also estimated. The increase
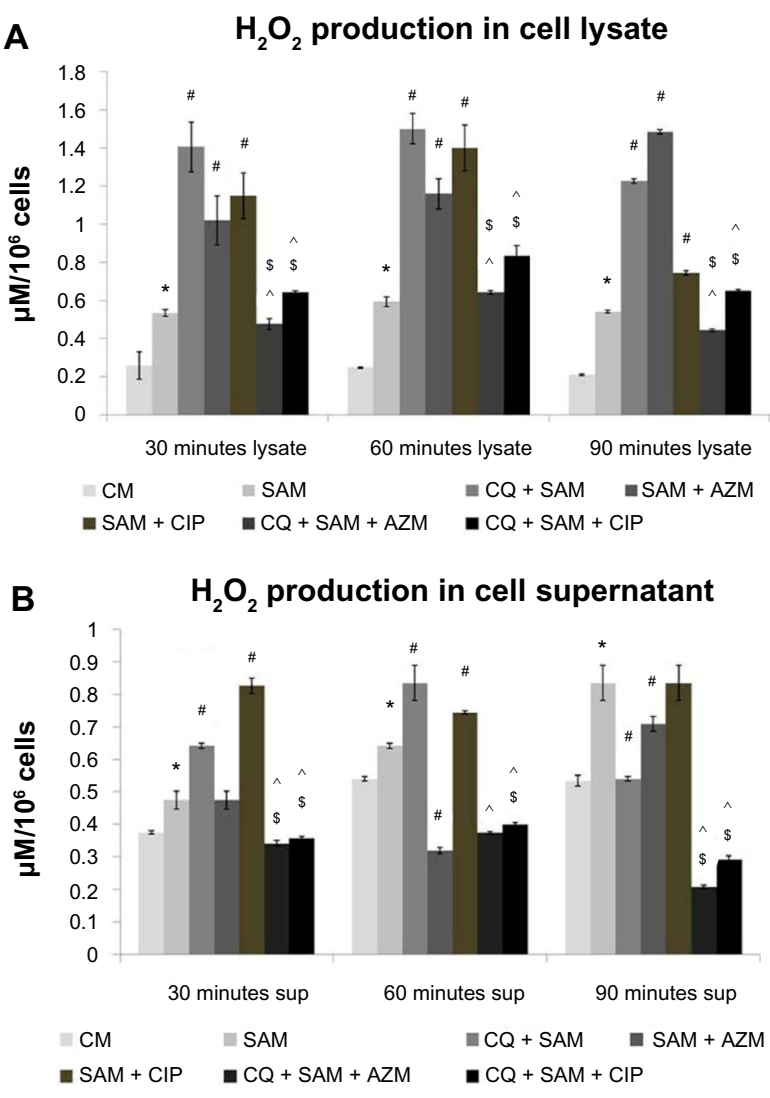

Figure 2 Effect of chloroquine (CQ) and antibiotic treatment on Staphylococcus aureus infection-induced alteration in $\mathrm{H}_{2} \mathrm{O}_{2}$ release in the lysate and supernatant in murine peritoneal macrophages. The lysate (A) and supernatant (sup) (B) recovered after time-dependent phagocytosis in the presence or absence of chloroquine or antibiotics were used to determine the $\mathrm{H}_{2} \mathrm{O}_{2}$ release.

Notes: $\mathrm{H}_{2} \mathrm{O}_{2}$ release is expressed in terms of $\mu \mathrm{M} / 10^{6}$ cells. Results are presented as mean \pm standard deviation of three independent experiments. *Significant difference with respect to $\mathrm{CM}$; " significant difference with respect to SAM; ^significant difference with respect to $C Q$ plus $S$. aureus-infected macrophages at the $P<0.05$ level of significance; ${ }^{\$}$ significant difference with respect to either ciprofloxacin (CIP) or azithromycin (AZM) plus S. aureus-infected macrophages.

Abbreviations: $C M$, control macrophages; $C Q+S A M$, chloroquinepretreated + S. aureus-infected macrophages; CQ + SAM + AZM, chloroquinepretreated macrophages infected with $S$. aureus and then treated with azithromycin; $\mathrm{CQ}+\mathrm{SAM}+\mathrm{CIP}$, chloroquine-pretreated macrophages infected with S. aureus and then treated with ciprofloxacin; SAM, S. aureus-infected macrophages; SAM + AZM, S. aureus-infected macrophages treated with azithromycin; SAM + CIP, S. aureusinfected macrophages treated with ciprofloxacin.

in the $\mathrm{O}_{2}^{-}$released in lysate (Figure $3 \mathrm{~A}$ ) and supernatant (Figure 3B) after different times of phagocytosis in the presence of $S$. aureus infection was found to be significant $(P<0.05)$ when compared with the $\mathrm{O}_{2}^{-}$release of noninfected control macrophages. A statistically significant increase in the amount of $\mathrm{O}_{2}^{-}$released both in the supernatant and lysate was observed $(P<0.05)$ in CQ-pretreated macrophages before infection, when compared with untreated S. aureus-infected macrophages at 30,60, and 90 minutes post-incubation (Figure $3 \mathrm{~A}$ and $\mathrm{B}$ ).

Treatment of macrophages with CIP and AZM before $S$. aureus infection resulted in an increased amount of $\mathrm{O}_{2}^{-}$being released into the supernatant and lysate at 30 and 
A

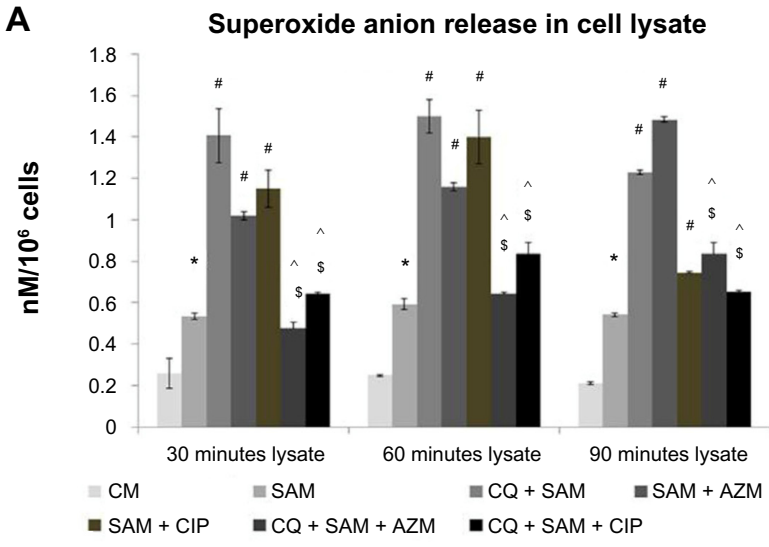

B Superoxide anion release in cell supernatant

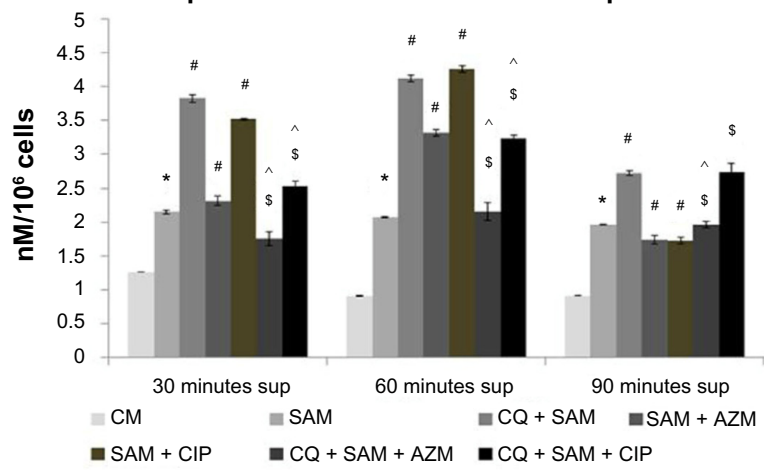

Figure 3 Effect of chloroquine (CQ) and antibiotic treatment on Staphylococcus aureus infection in the lysate and supernatant of murine peritoneal macrophages. The lysate (A) and supernatant (sup) (B) after time-dependent phagocytosis in the presence or absence of $\mathrm{CQ}$ or antibiotics were used to determine the release of superoxide anion.

Notes: Superoxide anion release is expressed in terms of $n M / 10^{6}$ cells. Results are presented as mean \pm standard deviation of three independent experiments. *Significant difference with respect to CM; "significant difference with respect to SAM; ^significant difference with respect to $C Q$ plus $S$. aureus-infected macrophages at the $P<0.05$ level of significance; ${ }^{\$}$ significant difference with respect to either ciprofloxacin (CIP) or azithromycin (AZM) plus S. aureus-infected macrophages.

Abbreviations: CM, control macrophages; $C Q+S A M$, chloroquine-pretreated plus S. aureus-infected macrophages; CQ + SAM + AZM, chloroquine-pretreated macrophages infected with $S$. aureus and then treated with azithromycin; CQ + SAM + CIP, chloroquine-pretreated macrophages infected with S. aureus and then treated with ciprofloxacin; SAM, S. aureus-infected macrophages; SAM + AZM, S. aureusinfected macrophages treated with azithromycin; SAM + CIP, S. aureus-infected macrophages treated with ciprofloxacin.

60 minutes but a decreased amount at 90 minutes in cell supernatant post-incubation when compared with untreated S. aureus-infected macrophages (Figure 3B). The amount of $\mathrm{O}_{2}^{-}$released significantly decreased in 30 and 60 minutes in both the supernatant and lysate in CQ-pretreated and AZM/ CIP-treated $S$. aureus macrophages but remained same at 90 minutes in supernatant when compared with CQ plus S. aureus-infected macrophages after phagocytosis. $\mathrm{O}_{2}^{-}$ release was significantly lower at 30,60 , and 90 minutes in the cell lysate and at 30 and 60 minutes in cell supernatant when CQ-pretreated macrophages were incubated with CIP or AZM before $S$. aureus infection compared with CIP- or
AZM-treated S. aureus-infected macrophages at 30, 60, and 90 minutes in the cell lysate (Figure 3A).

\section{Effect of chloroquine and antibiotic treatment on S. aureus infection-induced nitric-oxide production in the lysate and supernatant of murine peritoneal macrophages}

CQ inhibits NO production when added during the stimulation of peritoneal macrophages with $S$. aureus. A statistically significant decrease in the amount of NO released both in the lysate (Figure 4A) and supernatant (Figure 4B) was
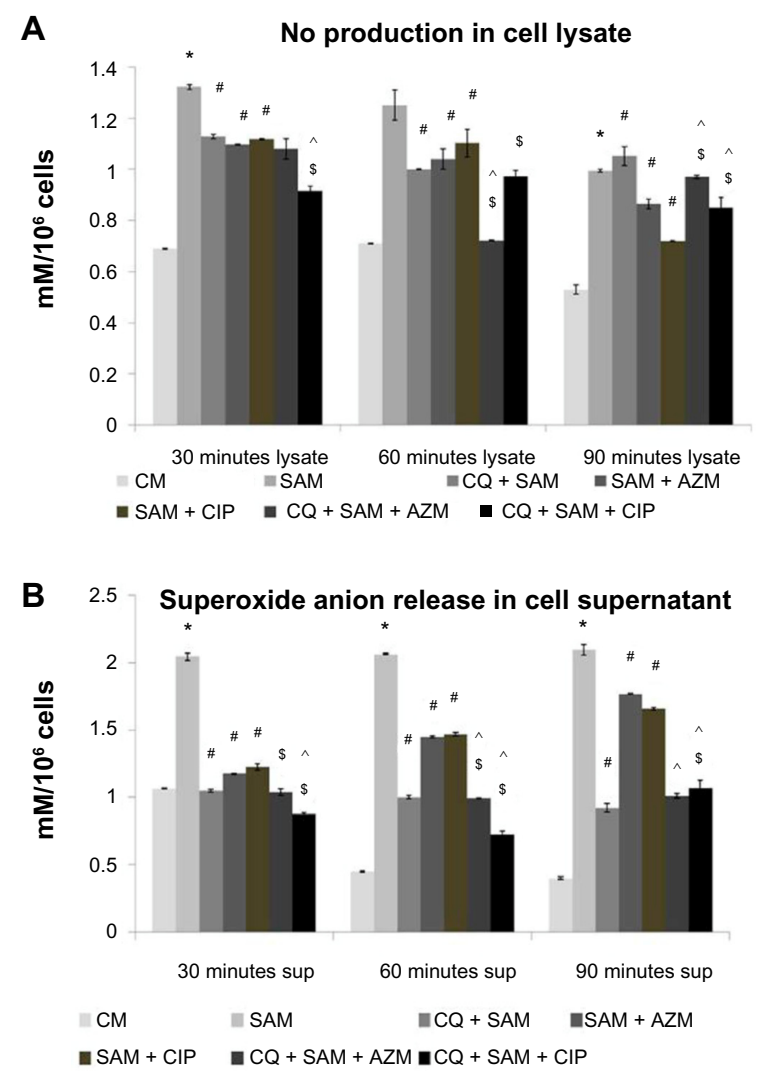

Figure 4 Effect of chloroquine (CQ) and antibiotic treatment on Staphylococcus aureus infection induced $\mathrm{NO}$ release in the lysate and supernatant in murine peritoneal macrophages. The lysate $(\mathbf{A})$ and supernatant $(\mathbf{B})$ recovered after timedependent phagocytosis in the presence or absence of $\mathrm{CQ}$ or antibiotics were used to determine the nitric-oxide release by Griess assay.

Notes: Nitric-oxide release is expressed in terms of $\mathrm{mM} / 10^{6}$ cells. Results are presented as mean \pm standard deviation of three independent experiments. *Significant difference with respect to CM; " significant difference with respect to SAM; 'significant difference with respect to $C Q$ plus $S$. aureus-infected macrophages at the $P<0.05$ level of significance; ${ }^{\$}$ significant difference with respect to either ciprofloxacin (CIP) or azithromycin (AZM) plus S. aureus-infected macrophages. Abbreviations: CM, control macrophages; $C Q+S A M$, chloroquine-pretreated plus S. aureus-infected macrophages; CQ + SAM + AZM, chloroquine-pretreated macrophages infected with $S$. aureus and then treated with azithromycin; CQ + SAM + $\mathrm{CIP}$, chloroquine-pretreated macrophages infected with S. aureus and then treated with ciprofloxacin; SAM, S. aureus-infected macrophages; SAM + AZM, S. aureusinfected macrophages treated with azithromycin; SAM + CIP, S. aureus-infected macrophages treated with ciprofloxacin. 
observed $(P<0.05)$ in CQ-pretreated macrophages before infection, compared with untreated $S$. aureus-infected macrophages at 30 and 60 minutes post-incubation. The amount of NO release decreased in the case of macrophages treated with AZM or CIP alone before $S$. aureus infection compared with untreated $S$. aureus-infected macrophages (Figure 4A and B). The NO release was significantly lower at 30 and 60 minutes in the supernatant and at 60 minutes in the cell lysate when CQ-pretreated macrophages were incubated with CIP or AZM before $S$. aureus infection, compared with CIP- or AZM-treated $S$. aureus-infected macrophages.

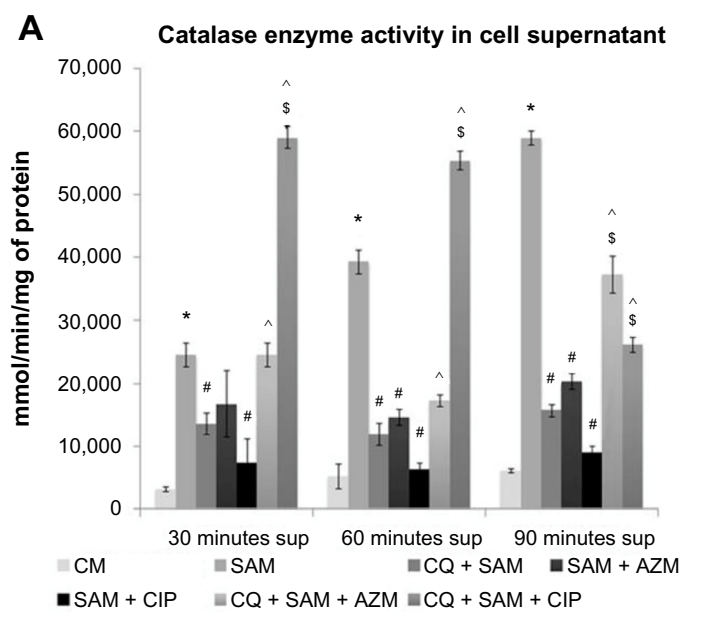

B

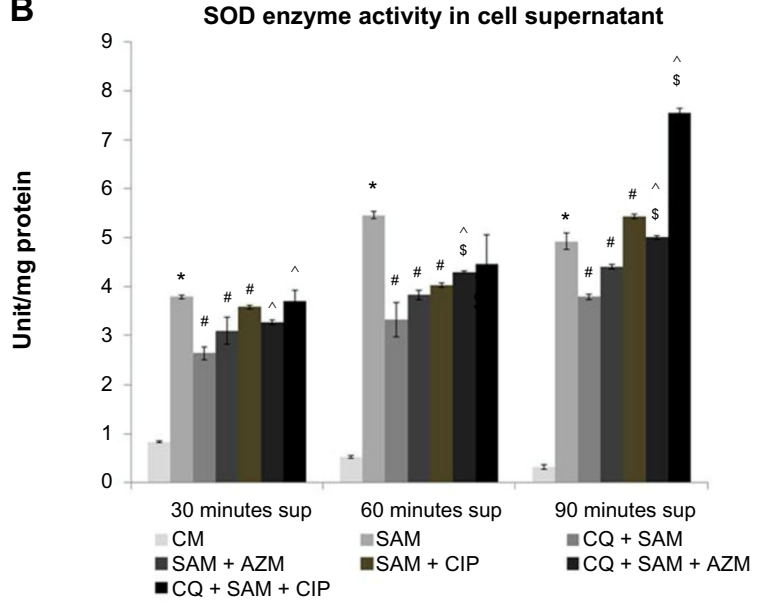

Effect of chloroquine and antibiotic treatment on S. aureus infection-induced alteration in the catalase enzyme activity in the supernatant and lysate of murine peritoneal macrophages

Figures $5 \mathrm{~A}$ and $6 \mathrm{~A}$ show a marked increase in the catalase enzyme activity in the supernatant and lysate of peritoneal macrophages infected with $S$. aureus after 30, 60, and 90 minutes of phagocytosis compared with the noninfected control group. A significant decrease in catalase enzyme activity was observed in the supernatants of CQ-treated
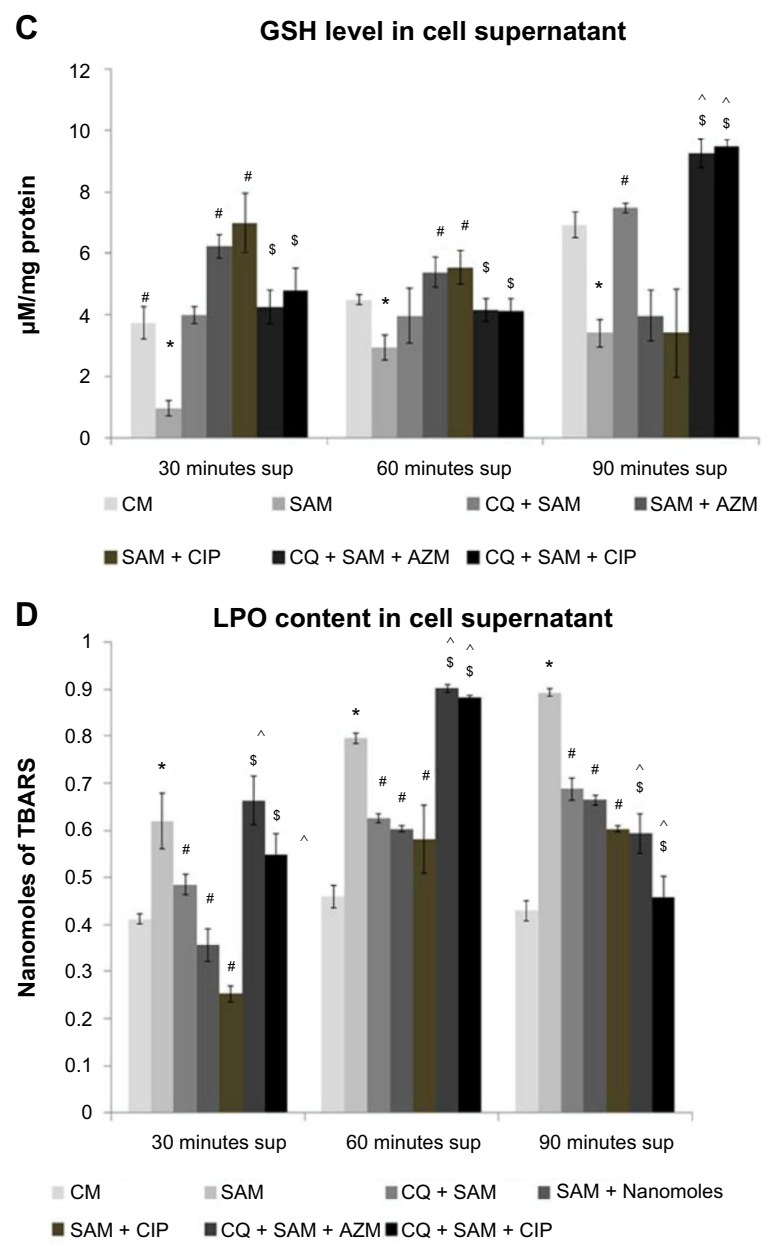

Figure 5 Effect of chloroquine (CQ) and antibiotic treatment on Staphylococcus aureus infection-induced alteration in catalase, superoxide dismutase (SOD) enzyme activity, glutathione (GSH) level, and lipid peroxidation (LPO) content in the supernatant in murine peritoneal macrophages. The supernatant (sup) was recovered after timedependent phagocytosis in the presence or absence of $\mathrm{CQ}$ or antibiotic treatment, as described in the "Methods and materials" section, and were used to determine the catalase (A), SOD enzyme activity (B), GSH level (C), and LPO content (D) in the supernatant.

Notes: Catalase enzyme activity was measured in the presence of $15 \mu$ moles of $\mathrm{H}_{2} \mathrm{O}_{2} / \mathrm{mL}$ of phosphate buffer and is expressed in terms of mmol/min mg protein (A); SOD activity is expressed in terms of SOD units/mg protein (B); GSH content is expressed in terms of $\mu$ M/mg protein (C); and LPO content is expressed in terms of nmol of thiobarbituric acid-reactive substances (TBARS) (D). Results are shown as mean \pm standard deviation of three independent experiments. *Significant difference with respect to $\mathrm{CM}$; " significant difference with respect to SAM; 'significant difference with respect to CQ plus $S$. aureus-infected macrophages at the $P<0.05$ level of significance; \$significant difference with respect to either ciprofloxacin (CIP) or azithromycin (AZM) plus S. aureus-infected macrophages.

Abbreviations: CM, control macrophages; CQ + SAM, chloroquine-pretreated plus S. aureus-infected macrophages; CQ + SAM + AZM, chloroquine-pretreated macrophages infected with S. aureus and then treated with azithromycin; CQ + SAM + CIP, chloroquine-pretreated macrophages infected with $S$. aureus and then treated with ciprofloxacin; SAM, S. aureus-infected macrophages; SAM + AZM, S. aureus-infected macrophages treated with azithromycin; SAM + CIP, S. aureus-infected macrophages treated with ciprofloxacin. 
A

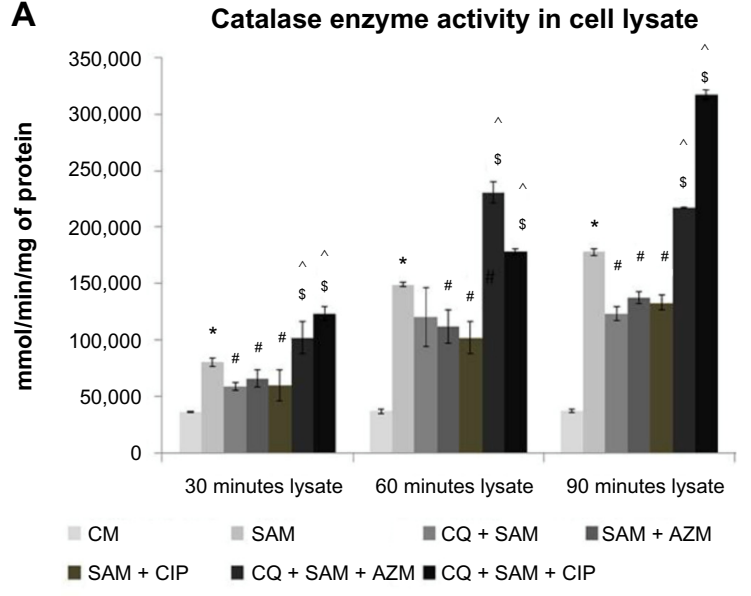

B

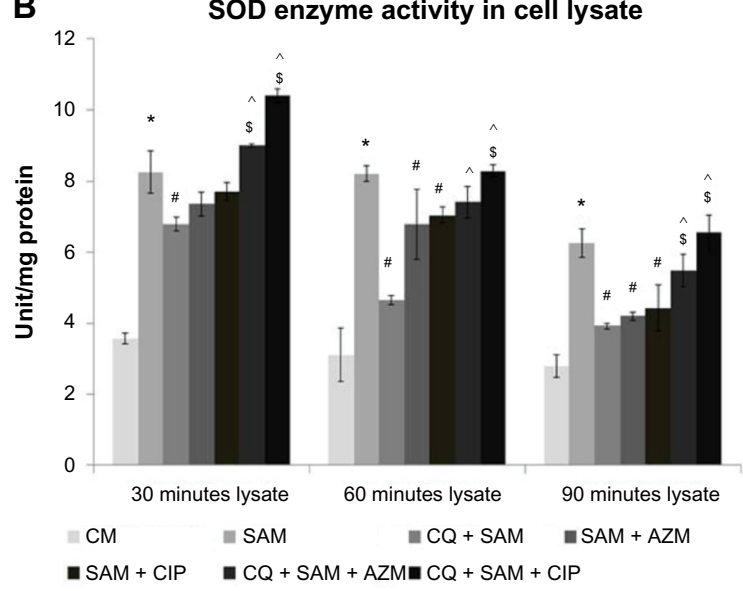

C

GSH level in cell lysate

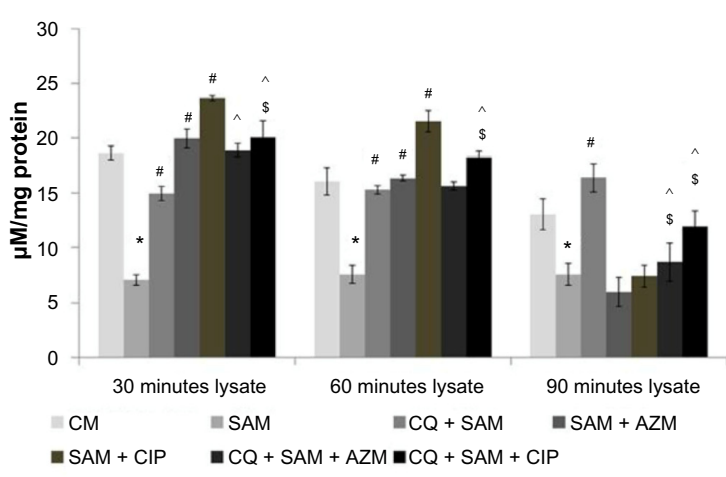

D $0.9 \quad$ LPO content in cell lysate

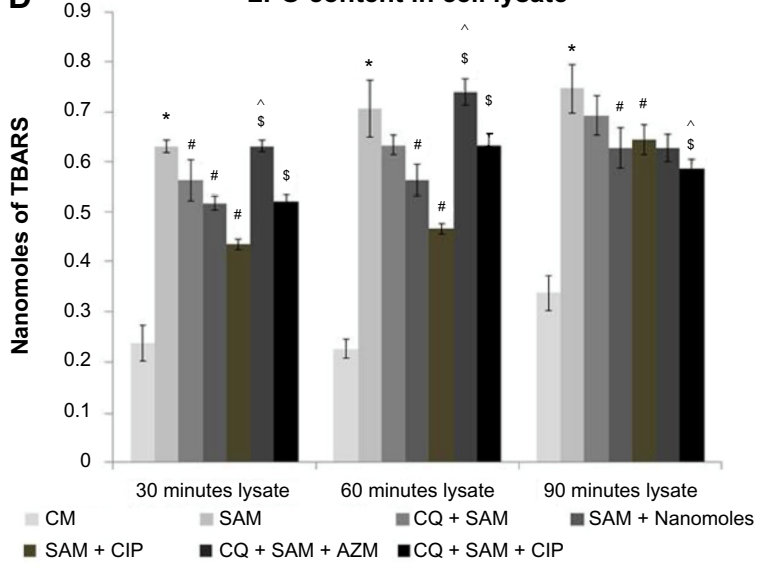

Figure 6 Effect of chloroquine (CQ) and antibiotic treatment on Staphylococcus aureus infection-induced alteration in catalase, superoxide dismutase (SOD) enzyme activity, glutathione (GSH) level, and lipid peroxidation (LPO) content in the lysate in murine peritoneal macrophages. The cell-free lysate was recovered after time-dependent phagocytosis in the presence or absence of $C Q$ or antibiotic treatment, as described in the "Methods and materials" section, and were used to determine the catalase (A), SOD enzyme activity (B), GSH level (C), and LPO content (D) in the lysate.

Notes: Catalase enzyme activity was measured in the presence of $15 \mu$ moles of $\mathrm{H}_{2} \mathrm{O}_{2} / \mathrm{mL}$ of phosphate buffer and is expressed in terms of millimoles/minute $\mathrm{mg}$ protein (A); SOD activity is expressed in terms of SOD units/mg protein (B); GSH content is expressed in terms of $\mu \mathrm{M} / \mathrm{mg}$ protein (C); and LPO content is expressed in terms of $\mathrm{nmol}$ of thiobarbituric acid-reactive substances (TBARS) (D). Results are shown as mean \pm standard deviation of three independent experiments. *Significant difference with respect to CM; "significant difference with respect to SAM; ^significant difference with respect to CQ plus S. aureus-infected macrophages at the $P<0.05$ level of significance; \$significant difference with respect to either ciprofloxacin (CIP) or azithromycin (AZM) plus S. aureus-infected macrophages.

Abbreviations: CM, control macrophages; CQ + SAM, chloroquine-pretreated plus S. aureus-infected macrophages; CQ + SAM + AZM, chloroquine-pretreated macrophages infected with $S$. aureus and then treated with azithromycin; CQ + SAM + CIP, chloroquine-pretreated macrophages infected with $S$. aureus and then treated with ciprofloxacin; SAM, S. aureus-infected macrophages; SAM + AZM, S. aureus-infected macrophages treated with azithromycin; SAM + CIP, S. aureus-infected macrophages treated with ciprofloxacin.

murine peritoneal macrophages before infection compared with in those of the CQ non-treated infected group. Treatment of macrophages with either CIP or AZM before $S$. aureus infection decreased the amount of catalase enzyme activity in the supernatant compared with the amount found in untreated S. aureus-infected macrophages (Figure 5A). However treatment of $S$. aureus with AZM increased catalase activity both in the supernatant and lysate in comparison to treatment with CIP but the catalase production was less compared with that in untreated S. aureus-infected macrophages. This increase in the catalase enzyme activity was even more prominent when CQ-pretreated macrophages were incubated with CIP rather than with AZM before $S$. aureus infection in comparison to CQ plus $S$. aureus-infected macrophages at 30,60 , and 90 minutes in both supernatant and lysate (Figures 5A and 6A).

\section{Effect of chloroquine and antibiotic treatment on S. aureus infection-induced alteration in the superoxide dismutase enzyme activity in the supernatant and lysate of murine peritoneal macrophages}

Figures $5 \mathrm{~B}$ and $6 \mathrm{~B}$ show that there was a significant increase in the SOD enzyme activity in the supernatant and lysate 
of peritoneal macrophages infected with $S$. aureus after 30 , 60, and 90 minutes of phagocytosis compared with in the noninfected control group $(P<0.05)$. A significant decrease in the SOD enzyme activity was observed in the supernatants and lysates of CQ-treated murine peritoneal macrophages before infection compared with in the CQ non-treated infected group. Treatment of macrophages with either CIP or AZM alone before $S$. aureus infection resulted in decreased SOD enzyme activity at all time intervals in the lysate and only at 30 and 60 minutes in the supernatant when compared with untreated $S$. aureus-infected macrophages. The activity of SOD enzyme was found to increase at 30 , 60 , and 90 minutes in both supernatant and lysate when CQpretreated macrophages were incubated with CIP or AZM before $S$. aureus infection in comparison to in CQ-pretreated $S$. aureus-infected macrophages, however the enzyme activity was found to increase with time in the supernatant of CQ- and CIP-pretreated S. aureus-infected macrophages (Figure 5B).

\section{Effect of chloroquine and antibiotic treatment on S. aureus infection-induced alteration in the glutathione content in the supernatant and lysate of murine peritoneal macrophages}

The GSH content in the supernatant (Figure 5C) and lysate (Figure 6C) was significantly lower $(P<0.05)$ in $S$. aureusinfected macrophages than in control macrophages at 30 , 60 , and 90 minutes after $S$. aureus infection. A statistically significant increase in the amount of GSH in the lysate was observed $(P<0.05)$ in CQ-pretreated macrophages before infection at 30,60, 90 minutes post-incubation, when compared with in untreated $S$. aureus-infected macrophages (Figure 6C).

Macrophages pretreated with AZM or CIP alone before $S$. aureus infection showed an increased amount of GSH content at 30 and 60 minutes in the supernatant and lysate but a decreased amount at 90 minutes post-incubation when compared with the amount of GSH released by untreated S. aureusinfected macrophages. However, administration of CIP or AZM to the CQ-pretreated macrophages before $S$. aureus infection increased the GSH content in the supernatant at 90 minutes compared with in the CQ plus $S$. aureus-infected macrophages (Figure 5C). Compared with CIP- or AZMtreated S. aureus-infected macrophages, there was less GSH production observed in both the supernatant and lysate at 30 and 60 minutes but increased GSH production at 90 minutes in the cell supernatant in CQ-pretreated macrophages incubated with CIP or AZM before $S$. aureus infection.

\section{Effect of chloroquine and antibiotic treatment on S. aureus infection-induced alteration in the lipid peroxidation level in the supernatant and lysate of murine peritoneal macrophages}

The amount of LPO released in the supernatant (Figure 5D) and lysate (Figure 6D) was significantly higher $(P<0.05)$ in $S$. aureus-infected macrophages than in control macrophages at 30,60, and 90 minutes after $S$. aureus infection. A statistically significant decrease in LPO production in the supernatant and lysate was observed $(P<0.05)$ in CQ-pretreated macrophages at 30,60, and 90 minutes post-incubation in the cell supernatant as well as at 30 minutes in lysate when compared with untreated $S$. aureus-infected macrophages (Figures 5D and 6D).

Macrophages pretreated either with CIP or AZM alone before $S$. aureus infection also showed decreased production of LPO in the supernatant and lysate in comparison with that released in untreated $S$. aureus-infected macrophages. However, administration of either CIP or AZM to the CQ-pretreated macrophages before $S$. aureus infection increased LPO release, both in supernatant and lysate at 30 and 60 minutes when compared with CQ plus S. aureusinfected macrophages (Figures 5D and 6D). Compared with in CIP- or AZM-treated S. aureus-infected macrophages, the LPO released was significantly higher after 30 and 60 minutes in supernatant and lysate, respectively, in CQ-pretreated macrophages incubated with CIP or AZM before $S$. aureus infection (Figures 5D and 6D).

\section{Effect of chloroquine and antibiotic treatment on S. aureus infection-induced alteration in the lysozyme enzyme activity in the supernatant and lysate of murine peritoneal macrophages}

Table 1 shows there was a significant increase in the lysozyme enzyme activity in the supernatant and lysate of peritoneal macrophages infected with $S$. aureus after 30, 60, and 90 minutes of phagocytosis compared with in the noninfected control group $(P<0.05)$. A significant decrease in the lysozyme enzyme activity was observed in the supernatants and lysates of CQ-treated murine peritoneal macrophages before infection compared with in the non-CQ-treated infected group. Treatment of macrophages with either CIP 
Table I Effect of chloroquine (CQ) and antibiotic treatment on S. aureus infection-induced lysozyme enzyme activity in the supernatant and lysate by murine peritoneal macrophages

\begin{tabular}{|c|c|c|c|c|c|c|}
\hline \multirow[t]{2}{*}{ Group } & \multicolumn{3}{|c|}{$\begin{array}{l}\text { Lysozyme enzyme activity in supernatant, } \\
\text { units/mg of protein (mean } \pm \text { SD) }\end{array}$} & \multicolumn{3}{|c|}{$\begin{array}{l}\text { Lysozyme enzyme activity in lysate, units/mg of } \\
\text { protein (mean } \pm \text { SD) }\end{array}$} \\
\hline & $30 \mathrm{~min}$ & $60 \mathrm{~min}$ & $90 \mathrm{~min}$ & $30 \mathrm{~min}$ & $60 \mathrm{~min}$ & $90 \mathrm{~min}$ \\
\hline CM & $14.728 \pm 0.772$ & $17.350 \pm 0.660$ & $46.746 \pm 1.960$ & $10.860 \pm 0.550$ & $12.000 \pm 3.080$ & $7.600 \pm 1.980$ \\
\hline SAM & $* 231.450 \pm 7.930$ & $* 166.780 \pm 2.240$ & $* 104.540 \pm 4.320$ & $* 165.670 \pm 6.130$ & $* 224.930 \pm 4.000$ & $* 254.060 \pm 5.040$ \\
\hline $\mathrm{CQ}+\mathrm{SAM}$ & ${ }^{\#} 166.780 \pm 2.240$ & ${ }^{\#} 120.610 \pm 5.350$ & ${ }^{\#} 81.240 \pm 1.800$ & ${ }^{\# 1} 100.485 \pm 0.064$ & $\# 93.930 \pm 1.680$ & ${ }^{\#} 66.040 \pm 5.790$ \\
\hline SAM + AZM & ${ }^{\#} \mid 26.470 \pm 0.898$ & ${ }^{\#} 103.479 \pm 8.710$ & $86.160 \pm 5.340$ & $\# 73.770 \pm 1.870$ & $\# 93.930 \pm 1.600$ & ${ }^{\# 159.205 \pm 3.820}$ \\
\hline SAM + CIP & ${ }^{\#} 103.370 \pm 8.710$ & 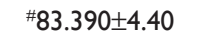 & $\# 55.380 \pm 2.250$ & ${ }^{\#} 70.915 \pm 10.760$ & ${ }^{\#} 85.690 \pm 7.000$ & ${ }^{\#} 101.417 \pm 7.570$ \\
\hline $\mathrm{CQ}+\mathrm{SAM}+\mathrm{AZM}$ & $\$ 167.970 \pm 2.480$ & $\$ 128.430 \pm 0.890$ & $\$ 34.740 \pm 3.510$ & $\$ 337.000 \pm 27.000$ & $\$ 212.640 \pm 0.960$ & $\AA 26.520 \pm 6.630$ \\
\hline$C Q+S A M+C I P$ & $\$ 77.980 \pm 2.680$ & $\$ 49.685 \pm 5.490$ & $\stackrel{\wedge}{\wedge} 29.110 \pm 2.460$ & $\$ 219.030 \pm 5.220$ & $\$ 165.790 \pm 4.410$ & ^II $0.900 \pm 0.800$ \\
\hline
\end{tabular}

Notes: The supernatants and cell-free lysates obtained in the phagocytosis assay were allowed to interact with a suspension of Micrococcus lysodeikticus in 0.15 M potassium phosphate buffer ( $\mathrm{pH} 6.2$, optical density fixed at $0.6-0.7$ at $450 \mathrm{~nm}$ ). One unit of lysozyme was defined as the amount of enzyme that produces a decrease in absorbance of $0.001 /$ minute at $450 \mathrm{~nm}$ and the lysozyme enzyme activity is expressed in terms of units/mg protein. Results are presented as the mean \pm standard deviation of three independent experiments. *Significant difference with respect to CM; \#significant difference with respect to SAM; ^significant difference with respect to CQ plus S. aureusinfected macrophages at the $P<0.05$ level of significance; ${ }^{\$}$ significant difference with respect to either ciprofloxacin (CIP) or azithromycin (AZM) plus $S$. aureus-infected macrophages.

Abbreviations: CM, control macrophages; CQ + SAM, chloroquine-pretreated plus S. aureus-infected macrophages; CQ + SAM + AZM, chloroquine-pretreated macrophages infected with S. aureus and then treated with azithromycin; CQ + SAM + CIP, chloroquine-pretreated macrophages infected with S. aureus and then treated with ciprofloxacin; SAM, S. aureus-infected macrophages; SAM + AZM, S. aureus-infected macrophages treated with azithromycin; SAM + CIP, S. aureus-infected macrophages treated with ciprofloxacin.

or AZM alone before $S$. aureus infection also resulted in a decreased amount of lysozyme enzyme activity in the supernatant and lysate compared with in the untreated S. aureusinfected macrophages (Table 1). However, the lysozyme enzyme activity was restored significantly in the lysate at 30 and 60 minutes when CQ-pretreated macrophages were incubated with either CIP or AZM before being infected with $S$. aureus in comparison with in CQ plus $S$. aureus-infected macrophages (Table 1). The lysozyme released was significantly higher at 30 and 60 minutes in supernatant and lysate, respectively, when $\mathrm{CQ}$-pretreated macrophages were incubated with CIP or AZM before being infected with $S$. aureus, compared with when CIP- or AZM-treated S. aureus-infected macrophages were not pretreated with $C Q$.

\section{Effect of chloroquine and antibiotic treatment on S. aureus infection-induced interferon gamma and tumor necrosis factor alpha production in murine peritoneal macrophages}

There was a significant $(P<0.05)$ gradual decrease in IFN- $\gamma$ (Figure 7A) and TNF- $\alpha$ (Figure 7B) levels in the media (culture supernatant) when phagocytic time increased in the presence of CQ at 60 and 90 minutes compared with the cytokine production after time-dependent phagocytosis in CQ non-treated infected macrophages. Macrophages pretreated either with CIP or AZM alone before $S$. aureus infection also showed reduced levels of TNF- $\alpha$ and IFN- $\gamma$ at both 60 and 90 mins in the supernatant in comparison to that released by the untreated $S$. aureus-infeccted macrophages. However, the levels of TNF- $\alpha$ and IFN- $\gamma$ decreased significantly in the medium at 90 minutes when CQ-pretreated macrophages were incubated with either CIP or AZM before being infected with S. aureus in comparison to CQ plus $S$. aureus-infected macrophages. The level of TNF- $\alpha$ decreased significantly in the medium at 60 and 90 minutes when CQ-pretreated macrophages were incubated with either CIP or AZM before being infected with $S$. aureus in comparison to CQ plus $S$. aureus-infected macrophages (Figure 7B).

\section{Discussion}

The intracellular persistence of $S$. aureus within macrophages, especially the antibiotic-resistant types, has posed serious problems and difficulties in the treatment of several diseases. Moreover, while it has been shown that cells take up antibiotics with known intracellular bactericidal activity, that they no longer confer protection in vitro. The possible reasons for this discrepancy are numerous: 1) the degree of plasma-membrane permeability may determine the concentration gradients of the antibiotic inside and outside of the cell; 2) antibiotics and bacteria may segregate subcellularly in diverse intracellular compartments, because of the dynamic exposure of the infectious agent to the unbound antibiotic drug fraction at the relevant effect site, resulting in a pharmacodynamic effect in in vivo conditions, whereas such a pharmacodynamic effect remains absent under the static in vitro conditions; 3) antibiotics may 
A
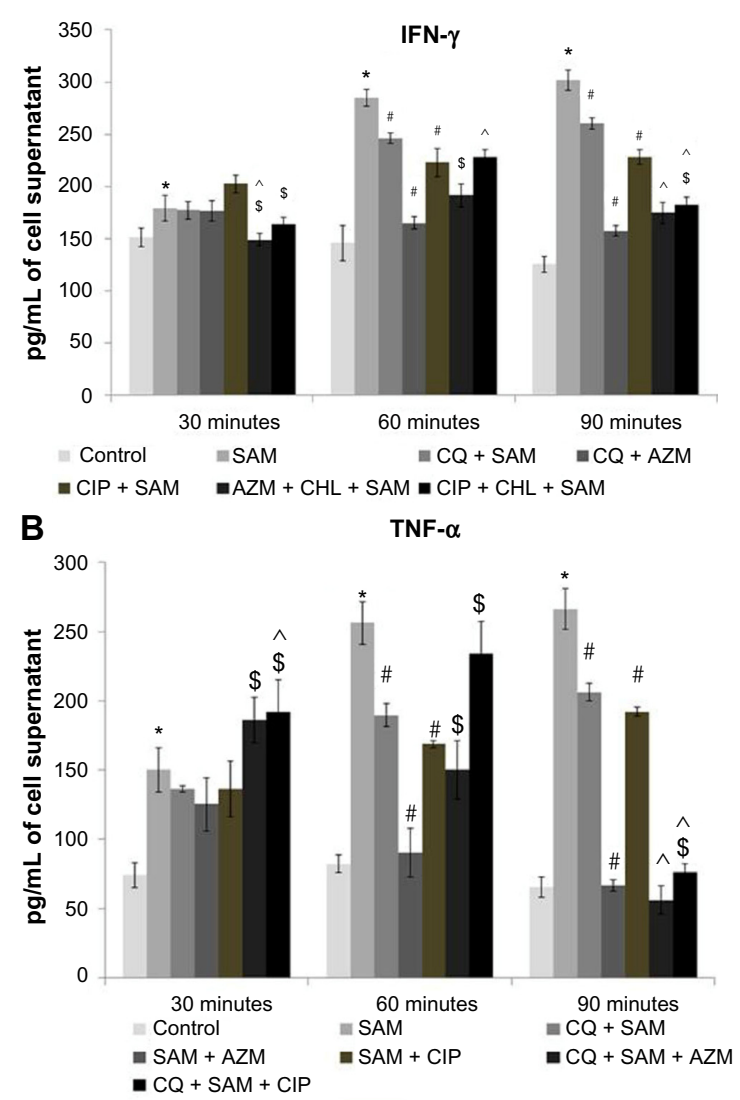

Figure 7 Levels of (A) interferon gamma (IFN- $\gamma$ ) and (B) tumor necrosis factor alpha (TNF- $\alpha$ ) in the supernatants collected from Staphylococcus aureus-infected macrophages in the presence or absence of chloroquine (CQ) or antibiotics were determined utilizing enzyme-linked immunosorbent assay according to the manufacturer's recommendations.

Notes: Results from triplicate experiments are presented. *Significant difference with respect to $\mathrm{CM}$; " significant difference with respect to SAM; "significant difference with respect to $C Q$ plus $S$. aureus-infected macrophages at the $P<0.05$ level of significance; ${ }^{\$}$ significant difference with respect to either ciprofloxacin (CIP) or azithromycin (AZM) plus S. aureus-infected macrophages.

Abbreviations: CM, control macrophages; CQ + SAM, chloroquine-pretreated plus S. aureus-infected macrophages; CQ + SAM + AZM, chloroquine-pretreated macrophages infected with $S$. aureus and then treated with azithromycin; CQ + SAM + CIP, chloroquine-pretreated macrophages infected with $S$. aureus and then treated with ciprofloxacin; SAM, S. aureus-infected macrophages; SAM + AZM, S. aureusinfected macrophages treated with azithromycin; SAM + CIP, S. aureus-infected macrophages treated with ciprofloxacin.

be inactivated by the intracellular milieu; and 4) differences in the physiological state of the internalized pathogen (resting vs dividing) can modulate the susceptibility to antibiotics. ${ }^{60}$ Another complicating factor is the extracellular multiplication of the surface-associated bacteria or those released from lysed infected cells, since these organisms would be subject to repeated endocytic events.

Efforts to obviate this difficulty by adding appropriate antibiotics and by restricting the entry of viable staphylococci associated with the cell's surface in vitro require a novel combination of drugs involving an efficacious antibiotic with intracellular bactericidal activity and an alkalinization of the intra-lysosomal $\mathrm{pH}$ by using CQ to enhance the uptake of antibiotics. Thus, the aim of our study was to formulate an efficacious combination using CQ (for alkalinization of the lysosomal $\mathrm{pH}$ ) to observe the effect of CIP and AZM on the killing of staphylococcal cells in isolated murine peritoneal macrophages and staphylococcal cells subsequent lysis to reduce the pathogen load within the phagocytic cells depending on the uptake of antibiotics. We chose mouse peritoneal macrophages as we could investigate phagocytosis within 2 hours of isolation, compared with in the 1 week required for differentiation of human monocyte-derived macrophages. ${ }^{61,62}$ Moreover, the peritoneal macrophages used in the study were elicited with thioglycolate broth, which did not potentially affect intracellular killing, as evident in our earlier studies. ${ }^{15-17}$ Therefore, the inclusion of data set by using untreated or nonelicited macrophages by thioglycolate broth, such as alveolar macrophages or splenic macrophages, was not essential in our study. When testing the CQ as a modulator of antibiotic uptake, several assays were performed: intracellular killing, ROS production, antioxidant enzymes, lysozyme release, and finally measurement of cytokines released by host cells in response to all these treatments before $S$. aureus infection. The rationale for performing these assays has already been mentioned in the "Materials and methods" section. These assays are very much linked and do not stand individually.

$\mathrm{CQ}$ (which neutralizes lysosomal $\mathrm{pH}$ ) in the presence of CIP or AZM strikingly increased the killing of intracellularly surviving $S$. aureus, as evident from the number of bacterial CFU (Figure 1). It has been reported that $\mathrm{pH}$ inside macrophage lysosomes seems to be 4.7 to $4.8 .{ }^{63}$ It was evident from both the mentioned reference and from our own study that CQ was taken up by macrophages most rapidly after 30 minutes when macrophages were exposed to 100 $\mu \mathrm{M} C Q .{ }^{63}$ It has been reported that the optimal $\mathrm{pH}$ for AZM accumulation in PMN is 8.7. ${ }^{64}$ Here, it can be suggested that AZM accumulated at its maximum level within 60 minutes of CQ treatment. In mouse peritoneal macrophages that had endocytosed fluorescein isothiocyanate-labeled dextran, Ohkuma and Poole determined that treatment with $100 \mu \mathrm{M}$ $\mathrm{CQ}$ raised the $\mathrm{pH}$ to $6.4 .{ }^{63}$ It was shown that the elevated $\mathrm{pH}$ value can remain stable for as long as 2 hours. ${ }^{65} \mathrm{CQ}$ causes a remarkable $\mathrm{pH}$ increase, even at $1 \mu \mathrm{M}$ concentration, and it has also been reported that a medium $\mathrm{pH}$ does not have any obvious effect on intra-lysosomal $\mathrm{pH} .{ }^{63}$ Intra-lysosomal $\mathrm{pH}$ may play an important role in the antimicrobial activity of macrophages. It is worth noting that the kinetics of the transient $\mathrm{pH}$ rise coincides with the phagocytic activity of the 
macrophages, such as respiratory burst with the degranulation of vesicles containing lysosomal enzymes. We did not actually quantify the $\mathrm{pH}$ in the phagosomes following $\mathrm{CQ}$ treatment; ${ }^{66}$ however, there are reports that can support our hypothesis in relation to the concentration of CQ and time of incubation used in our study. In another study, the treatment of human macrophages with $100 \mu \mathrm{M}$ CQ raised the $\mathrm{pH}$ of $C$. neoformans-laden phagosomes to $7.3 .{ }^{67}$ Indeed, in our study, the lysosomal bactericidal enzyme lysozyme, which requires an acid $\mathrm{pH}$, was inhibited in the CQ-pretreated macrophages. However, CQ in the presence of AZM or CIP significantly increased the release of lysozyme for the intracellular killing of $S$. aureus during early infection. CQ is a lysosomotropic agent that prevents endosomal acidification. It accumulates inside the acidic parts of the cell, including in the endosomes and lysosomes. This accumulation leads to the inhibition of lysosomal enzymes, which require an acidic $\mathrm{pH}$, and prevents the fusion of endosomes and lysosomes. The antirheumatic activity of CQ is thought to be related to its effects on lysosomal functions and protein processing. ${ }^{68}$ Based on the similar cationic and lysosomal accumulating properties, as well as interaction with membrane phospholipids, the action of CQ and AZM on a number of intracellular processes related to the killing of intracellular bacteria has been investigated. ${ }^{69}$ The present study indicates that due to AZM uptake (during the process of alkalinizing the lysosomal $\mathrm{pH}$ ) or lysozyme release during early infection presumably comes from the lysosomal compartment as a result of phagocytosis-induced degranulation. The alkalinization-induced killing of $S$. aureus by AZM causes more bactericidal lysozyme release during early infection and alters both the uptake and release of AZM in murine macrophages. It has also been reported that the ingestion of zymosan by human PMN modestly enhances the release of AZM. Agents like CQ are also reported to increase the efflux of AZM. ${ }^{70}$

CQ in the presence of antibiotics has been reported to improve the killing of bacteria where intra-macrophage survival plays a key step in disease pathogenesis. ${ }^{71}$ It has also been demonstrated that CQ inhibits intra-macrophage replication of Crohn's disease-associated Escherichia coli and enhances the antimicrobial effects of the antibiotics doxycycline and CIP. ${ }^{72}$ Several fluoroquinolone antibiotics are known to penetrate host cell membranes and accumulate at high concentrations intracellularly. ${ }^{73}$ In our study, at 30 and 60 minutes of incubation, we found that colony number decreases.

Also the bioavailability of CIP is elevated in humans in the presence of CQ. ${ }^{74}$ Recently, it has become apparent that at least some of the immunomodulatory effects of AZM are due to its action on macrophages. ${ }^{75}$ Previous studies have linked the immunomodulatory action of macrolides with changes in a variety of different molecular targets and signaling processes, including activation of the lysosomes in which AZM accumulates. ${ }^{76}$ We hypothesized that the effect of CQ-induced alkalinization on intra-lysosomal $\mathrm{pH}$ might be reduced at 90 minutes postinfection, subsequently leading to less uptake of AZM (as acid $\mathrm{pH}$ conditions markedly decrease the activity of macrolides). Due to the reduced uptake of AZM by the macrophages, the killing of intracellular bacteria would be reduced and ultimately result in the survival of intracellular $S$. aureus at 90 minutes postinfection. AZM is an antibacterial agent that, together with other members of the macrolide group of antibiotics, has been shown under a variety of clinical and experimental conditions to exert anti-inflammatory and immunomodulatory actions. ${ }^{77}$ Other studies on the intracellular accumulation and activity of CIP using different cellular models of $S$. aureus-infected phagocytes have also reported a bacteriostatic rather than bactericidal effect of fluoroquinolone. ${ }^{78}$ These concordant data clearly indicate that as yet unknown factors must have worked together to decrease the intracellular antibiotic efficiency of fluoroquinolone.

CIP, a quinolone antibiotic, is lysosomotropic and has been found to induce apoptosis (cell death) acting independently from ROS. ${ }^{79}$ On the other hand, an in vitro combination of CIP and CQ was reported to have a significant additive effect on a clinical isolate of Plasmodium falciparum. ${ }^{80}$ Macrophage phagocytosis is associated with a burst of respiratory activity that results in the production of a variety of molecules and free radicals called ROS, such as superoxide anion and $\mathrm{H}_{2} \mathrm{O}_{2}$. These ROS can damage lipids, proteins, and nucleic acids. LPO level has been used as a marker of oxidative stress. SOD, catalase, and GSH are important scavengers of superoxide anion and $\mathrm{H}_{2} \mathrm{O}_{2}$. These enzymes protect the generations of hydroxyl radicals and protect the cellular constituents from oxidative damage. As ROS and nitrogen intermediates are the key players in the clearance of intracellular pathogens (in macrophages), we hypothesized that the antioxidant and antiinflammatory properties of CIP or AZM might be responsible for the killing of the intracellular pathogens tested. To validate our hypothesis, CQ-treated/-untreated macrophages were infected with $S$. aureus to induce the generation of ROS and $\mathrm{NO}$ in the cells, and the amounts of $\mathrm{H}_{2} \mathrm{O}_{2}$, superoxide anion, and NO released in the supernatant as well as in the cell-free lysate were analyzed in these cells with and without CIP or AZM treatment. The increased killing of bacterial cells in 
the CQ-treated macrophages that was found may be due to greater production of $\mathrm{H}_{2} \mathrm{O}_{2}$ and superoxide anion, and this result may be because of the bactericidal action of $\mathrm{CQ} .{ }^{81}$ More killing of bacterial cells has been observed with AZM and CIP treatment in CQ-pretreated infected macrophages but less production of $\mathrm{H}_{2} \mathrm{O}_{2}$ was observed in our study. This may be because macrolides like AZM inhibit ROS production (which is time dependent). ${ }^{82}$

GSH, being the major intracellular thiol, provides protection against oxidative injury. GSH depletion may be associated with augmentation of an oxidative stress-mediated production of proinflammatory cytokines, particularly TNF- $\alpha$ and IFN- $\gamma$, because GSH is reported to play an important role in the polarization of Th1/Th2 balance. ${ }^{83}$ The increase of GSH and decrease of LPO in CQ-treated groups may be indicators of a reduction in oxidative stress, which is more prominent when CQ is combined with AZM/CIP. ${ }^{84}$

In this study, the oxidative stress generated by the macrophages was well orchestrated by the antioxidant defense mechanism of the cell, as was quite noticeable from the enhanced catalase and SOD activity in the supernatant as well as in the lysate when the CQ-pretreated macrophages were incubated with CIP or AZM before $S$. aureus infection. The observed increases in catalase activity may be as a result of cell-mediated immunity involving macrophages that may have provided several highly reactive molecules and ions such as $\mathrm{H}_{2} \mathrm{O}_{2}$, hydroxyl ions, and oxygen ions. The reason for this observed result may be due to the fact that the same site produces superoxide anion for dismutation to $\mathrm{H}_{2} \mathrm{O}_{2}$, the substrate for catalase, and glutathione peroxidase. The latter enzyme was not considered in this study and the possibility exists that this enzyme may have been involved in the neutralization of and conversion of $\mathrm{H}_{2} \mathrm{O}_{2}$. In addition, this enzyme has been reported to react with superoxide and hydroxyl radicals. It has also been reported that catalase activity is extended when cells are treated with pharmacological agents that delay proteolysis by decreasing lysosome acidification. ${ }^{85}$ As internalized catalase (as was evident in the lysate after 90 minutes) has access to intracellular oxidants diffusing from all directions, intracellular catalase has the potential to be more effective than catalase released in the medium after 90 minutes. Therefore, the intracellular delivery of catalase may permit effective interception and detoxification of ROS produced inside the cells and diffusing through the plasma membrane from released activated macrophages. ${ }^{86}$ It has been reported that catalase delivered by nanoparticles affected antioxidant protection for over 2 hours following internalization. It has also been found that this therapeutic time window can be further extended by the use of drugs, which either inhibit $\mathrm{pH}$-dependent lysosomal proteolysis or prevent microtubule-dependent lysosomal trafficking. ${ }^{85}$ Enhanced catalase activity in the AZM-pretreated group in our study may be because of the anti-inflammatory property of macrolides. The increase in catalase activity might be a defense mechanism for the bacteria. Enzyme activities are affected by many factors, including temperature, $\mathrm{pH}$, and enzyme inhibitors/activators. Enzyme-catalyzed reaction rate, which is usually used to measure enzyme activity, is also affected by the concentration of the substrate and enzyme. The anti-inflammatory activity of macrolides may reduce oxidative response, and sequentially reduce production of ROS, including the substrate of catalase, $\mathrm{H}_{2} \mathrm{O}_{2}$.

This raises the possibility that pharmacological agents that are already approved for clinical use in rheumatoid arthritis (here, CQ) in combination with antibiotics (AZM or CIP) to improve the in vivo efficacy of AZM uptake is an approach with the potential to enhance therapeutic intervention in acute pathological conditions associated with infection-induced oxidative stress, inflammation, and septic shock. ${ }^{87}$

The presence of intracellular $S$. aureus at 90 minutes postinfection in the macrophages pretreated with $\mathrm{CQ}$ and those incubated with CIP/AZM before being infected with S. aureus (due to less AZM uptake and less alkalinization induced by $\mathrm{CQ}$ ) may automatically trigger the synthesis of SOD. This may point to the fact that the induced oxidative stress seen in the decline in LPO level in the combinedtreatment group may not have necessitated the use of SOD to its optimum level. The substrate for this enzyme may have emerged as a result of xenobiotic metabolism. The reason for the observed increase in SOD activity in this study may be the result of the combined effect of intracellular $S$. aureus and CQ metabolism through a biotransformation pathway that may produce superoxide anion. ${ }^{88}$

Our study reveals that CQ treatment in the presence of AZM/CIP decreases the level of proinflammatory cytokines, particularly TNF- $\alpha$ and IFN- $\gamma$, which agrees with the report that CQ is effective in the treatment of diseases associated with the increased release of proinflammatory cytokines. ${ }^{89,90}$ Some recent studies have shown that CQ administration attenuates the production of TNF- $\alpha$; others have confirmed that CQ exerts some anti-inflammatory effects through downregulation of TNF- $\alpha$ production and signaling in macrophages as well as cytokine pattern production. TNF- $\alpha$ was able to enhance the oxidative response of optimally stimulated PMN and interfere with macrolides. An increased uptake of AZM has been reported in IFN- $\gamma$ - and TNF- $\alpha$-treated 
human macrophages and IFN- $\gamma$-treated THP-1 cells. ${ }^{62,89,90}$ In the murine macrophage cell line RAW 264.7, $100 \mu \mathrm{M}$ CQ interfered with the post-translational processing of TNF- $\alpha .{ }^{62}$ Alkalinizing agents including CQ inhibit the expression and release of TNF- $\alpha$ from Candida-stimulated human peripheral blood mononuclear cells. ${ }^{62}$ Our findings are supported by a previous study evaluating the effect of CQ $(100 \mu \mathrm{M})$ on TNF- $\alpha$ release from human whole blood showing that CQ interferes with TNF- $\alpha$ release in human cells at physiologic concentrations. A previous study using murine monocytic cell lines which demonstrated that CQ $(100 \mu \mathrm{M})$ inhibited lipopolysaccharides-stimulated TNF- $\alpha$ release also supports our study. ${ }^{91}$ Anti-mycobacterial synergy between TNF- $\alpha$ and AZM has been reported in a model of human macrophages. The same group observed increased uptake of AZM by macrophages in the presence of TNF $\alpha$ or IFN- $\gamma \cdot{ }^{92}$ Similarly, it has been shown that IFN- $\gamma$ enhances the cellular accumulation of AZM in the human myelomonocytic cell line THP-1. In earlier studies on RAW 264.7 macrophage cell lines, it was reported that $\mathrm{CQ}, \mathrm{AZM}$, and several other macrolides inhibited proinflammatory cytokine production. ${ }^{76}$

Previous research marked the transition of antimalarial agents from the treatment of malaria to that of rheumatic diseases. ${ }^{96}$ However, the clinical implication of our data in relation to $S$. aureus infection-induced arthritis or sepsis might be speculative. TNF- $\alpha$ and IFN- $\gamma$ are critical for the development of both innate and adaptive immune response. On the other hand, it has been argued that the pathogenesis of septic shock and arthritis involves the deregulated production of TNF- $\alpha$ and IFN- $\gamma$ and other proinflammatory mediators. ${ }^{93}$ Therefore, numerous studies ${ }^{94}$ have postulated that the immunomodulation of proinflammatory cytokines like TNF- $\alpha$ and IFN- $\gamma$ would reduce sepsis-related morbidity and mortality. By further dissecting the mechanism by which CQ in the presence of AZM reduces TNF- $\alpha$ and IFN- $\gamma$ release and ROS production, it might be possible to design congeners with either greater or lesser anti-inflammatory properties. Such drugs in combination could prove more efficacious in certain disease states.

Previous work has indicated that, for optimal NO production, macrophages need to be primed with IFN- $\gamma$. Moreover, TNF- $\alpha$ was able to enhance the oxidative response of macrophages and prime the effect of AZM uptake. ${ }^{95}$ Since acid $\mathrm{pH}$ inhibits CQ accumulation in macrophages, ${ }^{97}$ we hypothesized that at 90 minutes there might be less CQ and that the alkalinizing effect of CQ on phagosomes would withdraw; as a result of this, we postulated that there would be less uptake of AZM and this would subsequently lead to reduced TNF- $\alpha$ and IFN- $\gamma$ production. Therefore, due to the priming effect induced by TNF- $\alpha$ and IFN- $\gamma$ on AZM uptake, NO production is also limited and the number of bacteria that survive intracellularly within the macrophages is increased by suppressing the induction of inducible NO synthase messenger RNA in a dose-dependent manner. ${ }^{98} \mathrm{NO}$ production is further reduced when AZM is administered after CQ pretreatment of infected macrophages, thus inhibiting the production of harmful hydroxyl radicals and peroxynitrite ions further confirming immunomodulatory action of CQ by protecting host cells. ${ }^{99}$

CQ is commonly used to study the role of endosomal acidification in cellular processes such as intracellular TLR signaling. ${ }^{100}$ CQ's antagonistic effect on TLRs and cytokines is reported to be potentially relevant and beneficial to arthritis. ${ }^{101}$ In order to function, intracellular TLRs require an acidic $\mathrm{pH}$; probably they are proteolyzed by acid-dependent proteases that function normally within the acidic endoplasm of lysosomes. CQ, by altering the lysosomal $\mathrm{pH}$, possibly prevents the functional transformation of intracellular TLRs and inhibits their function. Research published recently proposes that TLR antagonism by CQ might not be driven entirely by endosomal $\mathrm{pH}$ alteration but by mechanical inhibition, whereby antimicrobial agents structurally bind to nucleic acids and mask their TLRbinding epitopes. ${ }^{102,103}$

\section{Conclusion}

This study aimed to determine if there was any alteration in the killing of $S$. aureus in murine peritoneal macrophages when CQ was used alone compared with in combination with CIP or AZM, and also to find out the implications of ROS production and cytokine release in the intracellular killing of $S$. aureus by the macrophages. It was found that $S$. aureus-triggered cytokine response was regulated when the macrophages were co-cultured with CQ and AZM as compared with CQ stimulation only. It can be suggested that the action of AZM in mediating bacterial killing is enhanced in the presence of $C Q$, indicating that there is an enhanced uptake of AZM during early infection that may be essential for the killing of bacteria by AZM. Reduction of the oxidative stress burden on the $S$. aureus-infected macrophages may pave the way for better killing of internalized $S$. aureus by CQ plus CIP or CQ plus AZM. Based on these observations, it can be concluded that CQ loaded with AZM elicits a stronger proinflammatory response by increasing the intracellular uptake of AZM thus enabling the immune system to mount a more robust and prolonged response against intracellular pathogens. 


\section{Acknowledgments}

This work was supported by a grant from the Department of Biotechnology, Government of West Bengal, Calcutta, West Bengal, India (grant number: vide sanction order 786-BT/ Estt/RD-4/13; date: October 30, 2013) to Biswadev Bishayi. Biswadev Bishayi is indebted to the Department of Science and Technology, Government of India, for providing the instruments procured under the Department of Science and Technology Promotion of University Research and Scientific Excellence program to the Department of Physiology, University of Calcutta.

\section{Disclosure}

The authors declare no conflicts of interest in this work. The authors also state that they have no direct financial relation with the commercial identities mentioned in this paper that might lead to a conflict of interest.

\section{References}

1. Lowy FD. Staphylococcus aureus infections. NEngl J Med. 1998;339(8): 520-532.

2. Brouillette E, Grondin G, Shkreta L, Lacasse P, Talbot BG. In vivo and in vitro demonstration that Staphylococcus aureus is an intracellular pathogen in the presence or absence of fibronectin-binding proteins. Microb Pathog. 2003;35(4):159-168.

3. Gordon RJ, Lowy FD. Pathogenesis of methicillin-resistant Staphylococcus aureus infection. Clin Infect Dis. 2008;46 Suppl 5: S350-S359.

4. Carryn S, Chanteux H, Seral C, Mingeot-Leclercq MP, Van Bambeke F, Tulkens PM. Intracellular pharmacodynamics of antibiotics. Infect Dis Clin North Am. 2003;17(3):615-634.

5. van den Broek PJ. Antimicrobial drugs, microorganisms, and phagocytes. Rev Infect Dis. 1989;11(2):213-245.

6. Krut O, Sommer H, Krönke M. Antibiotic-induced persistence of cytotoxic Staphylococcus aureus in non-phagocytic cells. J Antimicrob Chemother. 2004;53(2):167-173.

7. Al-Nawas B, Shah PM. Intracellular activity of ciprofloxacin and moxifloxacin, a new 8-methoxyquinolone, against methicillin-resistant Staphylococcus aureus. J Antimicrob Chemother. 1998;41(6): 655-658.

8. Foster TJ. Immune evasion by staphylococci. Nat Rev Microbiol. 2005; 3(12):948-958.

9. Zetola N, Francis JS, Nuermberger EL, Bishai WR. Community-acquired meticillin-resistant Staphylococcus aureus: an emerging threat. Lancet Infect Dis. 2005;5(5):275-286.

10. Hiramatsu K. Vancomycin-resistant Staphylococcus aureus: a new model of antibiotic resistance. Lancet Infect Dis. 2001;1(3):147-155.

11. Gresham HD, Lowrance JH, Caver TE, Wilson BS, Cheung AL, Lindberg FP. Survival of Staphylococcus aureus inside neutrophils contributes to infection. J Immunol. 2000;164(7):3713-3722.

12. Hudson MC, Ramp WK, Nicholson NC, Williams AS, Nousiainen MT. Internalization of Staphylococcus aureus by cultured osteoblasts. Microb Pathog. 1995;19(6):409-419.

13. Bayles KW, Wesson CA, Liou LE, Fox LK, Bohach GA, Trumble WR. Intracellular Staphylococcus aureus escapes the endosome and induces apoptosis in epithelial cells. Infect Immun. 1998;66(1):336-342.

14. Menzies BE, Kourteva I. Internalization of Staphylococcus aureus by endothelial cells induces apoptosis. Infect Immun. 1998;66(12): 5994-5998.
15. Das D, Saha SS, Bishayi B. Intracellular survival of Staphylococcus aureus: correlating production of catalase and superoxide dismutase with levels of inflammatory cytokines. Inflamm Res. 2008;57(7): 340-349.

16. Das D, Bishayi B. Staphylococcal catalase protects intracellularly survived bacteria by destroying $\mathrm{H} 2 \mathrm{O} 2$ produced by the murine peritoneal macrophages. Microb Pathog. 2009;47(2):57-67.

17. Das D, Bishayi B. Contribution of Catalase and Superoxide Dismutase to the Intracellular Survival of Clinical Isolates of Staphylococcus aureus in Murine Macrophages. Indian J Microbiol. 2010;50(4):375-384.

18. Lowy FD. Is Staphylococcus aureus an intracellular pathogen? Trends Microbiol. 2000;8(8):341-343.

19. Hamza T, Li B. Differential responses of osteoblasts and macrophages upon Staphylococcus aureus infection. BMC Microbiol. 2014;14:207.

20. Mal P, Dutta K, Bandyopadhyay D, Basu A, Khan R, Bishayi B. Azithromycin in combination with riboflavin decreases the severity of Staphylococcus aureus infection induced septic arthritis by modulating the production of free radicals and endogenous cytokines. Inflamm Res. 2013;62(3):259-274.

21. Mal P, Dutta S, Bandyopadhyay D, Dutta K, Basu A, Bishayi B. Gentamicin in combination with ascorbic acid regulates the severity of Staphylococcus aureus infection-induced septic arthritis in mice. Scand J Immunol. 2012;76(6):528-540.

22. Mal P, Ghosh D, Bandyopadhyay D, Dutta K, Bishayi B. Ampicillin alone and in combination with riboflavin modulates Staphylococcus aureus infection induced septic arthritis in mice. Indian J Exp Biol. 2012;50(10):677-689.

23. Rogers DE, Tompsett R. The survival of staphylococci within human leukocytes. J Exp Med. 1952;95(2):209-230.

24. Underhill DM, Goodridge H. Information processing during phagocytosis. Nat Rev Immunol. 2012;12(7):492-502.

25. Pechère JC. The activity of azithromycin in animal models of infection. Eur J Clin Microbiol Infect Dis. 1991;10(10):821-827.

26. van den Broek PJ. Activity of antibiotics against microorganisms ingested by mononuclear phagocytes. Eur J Clin Microbiol Infect Dis. 1991;10(2):114-118.

27. Tulkens PM. Intracellular distribution and activity of antibiotics. Eur J Clin Microbiol Infect Dis. 1991;10(2):100-106.

28. Seral C, Barcia-Macay M, Mingeot-Leclercq MP, Tulkens PM, Van Bambeke F. Comparative activity of quinolones (ciprofloxacin, levofloxacin, moxifloxacin and garenoxacin) against extracellular and intracellular infection by Listeria monocytogenes and Staphylococcus aureus in $\mathrm{J} 774$ macrophages. J Antimicrob Chemother. 2005;55(4):511-517.

29. Nguyen HA, Grellet J, Paillard D, Dubois V, Quentin C, Saux MC. Factors influencing the intracellular activity of fluoroquinolones: a study using levofloxacin in a Staphylococcus aureus THP-1 monocyte model. J Antimicrob Chemother. 2006;57(5):883-890.

30. Hall IH, Schwab UE, Ward ES, Ives T. Disposition and intracellular levels of moxifloxacin in human THP-1 monocytes in unstimulated and stimulated conditions. Int J Antimicrob Agents. 2003;22(6):579-587.

31. Labro MT. Immunomodulatory action of antibacterial agents. Clinical Immunotherapy. 1996;6(6):454-464.

32. Labro MT. Intraphagocytic penetration of macrolide antibiotics. In: Bryskier AJ, Butzler JP, Neu HC, Tulkens PM, editors. Macrolides: Chemistry, Pharmacology and Clinical Use. Paris: Arnette Blackwell; 1993:379-388.

33. Vergne I, Constant P, Lanéelle G. Phagosomal pH determination by dual fluorescence flow cytometry. Anal Biochem. 1998;255(1):127-132.

34. Poole B, Ohkuma S. Effect of weak bases on the intralysosomal $\mathrm{pH}$ in mouse peritoneal macrophages. J Cell Biol. 1981;90(3):665-669.

35. Chakravortty D, Hensel M. Inducible nitric oxide synthase and control of intracellular bacterial pathogens. Microbes Infect. 2005;5:621-627.

36. Pollock JD, Williams DA, Gifford MA, et al. Mouse model of X-linked chronic granulomatous disease, an inherited defect in phagocyte superoxide production. Nat. Genet. 1995;9:202-209. 
37. van Sorge NM, Beasley FC, Gusarov I, et al. Methicillin-resistant Staphylococcus aureus bacterial nitric-oxide synthase affects antibiotic sensitivity and skin abscess development. J Biol Chem. Mar 1, 2013;288(9):6417-6426.

38. Carlier MB, Garcia-Luque I, Montenez JP, Tulkens PM, Piret J. Accumulation, release and subcellular localization of azithromycin in phagocytic and non-phagocytic cells in culture. Int J Tissue React. $1994 ; 16(5-6): 211-220$.

39. Miossec-Bartoli C, Pilatre L, Peyron P, et al. The new ketolide HMR3647 accumulates in the azurophil granules of human polymorphonuclear cells. Anitmicrob Agents Chemother. 1999;43(10):2457-2462.

40. Carlier MB, Scorneaux B, Zenebergh A, Desnottes JF, Tulkens PM. Animal model pharmacokinetics and pharmacodynamics: a critical review. J Anitmicrob Agents Chemother. 1990;26 Suppl B:27-39.

41. Andes D, Craig WA. Animal model pharmacokinetics and pharmacodynamics: a critical review. Int J Antimicrob Agents. 2002; 19(4):261-268.

42. Maurin M, Raoult D. Phagolysosomal alkalinization and intracellular killing of Staphylococcus aureus by amikacin. J Infect Dis. 1994;169(2): 330-336.

43. Seral C, Van Bambeke F, Tulkens PM. Quantitative analysis of gentamicin, azithromycin, telithromycin, ciprofloxacin, moxifloxacin, and oritavancin (LY333328) activities against intracellular Staphylococcus aureus in mouse $\mathrm{J} 774$ macrophages. Antimicrob Agents Chemother. 2003;47(7):2283-2292.

44. Levitz SM, Nong SH, Seetoo KF, et al. Cryptococcus neoformans resides in an acidic phagolysosome of human macrophages. Infect Immun. 1999;67(2):885-890.

45. Augustijns P, Geusens P, Verbeke N. Chloroquine levels in blood during chronic treatment of patients with rheumatoid arthritis. Eur J Clin Pharmacol. 1992;42(4):429-433.

46. Newman SL, Gootee L, Brunner G, Deepe GS Jr. Chloroquine induces human macrophage killing of Histoplasma capsulatum by limiting the availability of intracellular iron and is therapeutic in a murine model of histoplasmosis. J Clin Invest. 1994;93(4):1422-1429.

47. Picot S, Peyron F, Vuillez JP, Polack B, Ambroise-Thomas P. Chloroquine inhibits tumor necrosis factor production by human macrophages in vitro. $J$ Infect Dis. 1991;164(4):830.

48. Yasuda H, Leelahavanichkul A, Tsunoda S, et al. Chloroquine and inhibition of Toll-like receptor 9 protect from sepsis-induced acute kidney injury. Am J Physiol Renal Physiol. 2008;294(5):F1050-F1058.

49. Thomé R, Moraes AS, Bombeiro AL, et al. Chloroquine treatment enhances regulatory $\mathrm{T}$ cells and reduces the severity of experimental autoimmune encephalomyelitis. Plos One. 2013;8(6):e65913.

50. Cooper RG, Magwere T. Chloroquine: novel uses and manifestations. Indian J Med Res. 2008;127(4):305-316.

51. Leigh PC, Van Furth R, Van Zwet TL. In vitro determination of phagocytosis and intracellular killing by polymorphonuclear and mononuclear phagocytes. In: Weir DM, editor. Handbook of Experimental Immunology. 4th ed. Oxford: Blackwell Scientific; 1986:1-46.

52. Absolom DR. Basic methods for the study of phagocytosis. Methods Enzymol. 1986;132:95-180.

53. Nandi D, Mishra MK, Basu A, Bishayi B. Protective effects of interleukin-6 in lipopolysaccharide (LPS)-induced experimental endotoxemia are linked to alteration in hepatic anti-oxidant enzymes and endogenous cytokines. Immunobiology. 2010;215(6):443-451.

54. Avci E, Akarslan ZZ, Erten H, Coskun-Cevher S. Oxidative stress and cellular immunity in patients with recurrent aphthous ulcers. Braz J Med Biol Res. 2014;47(5):355-360.

55. Sedlak J, Lindsay RH. Estimation of total, protein-bound, and nonprotein sulfhydryl groups in tissue with Ellman's reagent. Anal Biochem. 1968;25(1):192-205.

56. Colowick SP, Kaplan NO, Absolom DR. Basic methods for the study of phagocytosis. In: Sabato GD, Everse J, editors. Methods in Enzymology. Vol 132, Immunochemical techniques part J: phagocytosis and cell-mediated cytotoxicity. New York: Academic Press; 1986:160.
57. Bradford MM. A rapid and sensitive method for the quantitation of microgram quantities of protein utilizing the principle of protein-dye binding. Anal Biochem. 1976;72:248-254.

58. Bishayi B, Bandyopadhyay D, Majhi A, Adhikary R. Possible role of Toll-like receptor-2 in the intracellular survival of Staphylococcus aureus in murine peritoneal macrophages: involvement of cytokines and anti-oxidant enzymes. Scand J Immunol. 2014;80(2): 127-143.

59. Bishayi B, Bandyopadhyay D, Majhi A, Adhikary R. Expression of CXCR1 (Interleukin-8 Receptor) in Murine Macrophages After Staphylococcus aureus Infection and its Possible Implication on Intracellular Survival Correlating with Cytokines and Bacterial Anti-Oxidant Enzymes. Inflammation. Epub August 17, 2014. Available from: http://www.ncbi.nlm.nih.gov/pubmed/25129059. Accessed August 17, 2014.

60. Ignatowski TA, Bidlack JM. Differential kappa-opioid receptor expression on mouse lymphocytes at varying stages of maturation and on mouse macrophages after selective elicitation. J Pharmacol Exp Ther. 1999;290(2):863-870.

61. Polliack A, Gordon S. Scanning electron microscopy of murine macrophages. Surface characteristics during maturation, activation, and phagocytosis. Lab Invest. 1975;33(5):469-477.

62. Weber SM, Levitz SM. Chloroquine interferes with lipopolysaccharideinduced TNF-alpha gene expression by a nonlysosomotropic mechanism. J Immunol. 2000;165(3):1534-1540.

63. Ohkuma S, Poole B. Fluorescence probe measurement of the intralysosomal $\mathrm{pH}$ in living cells and the perturbation of $\mathrm{pH}$ by various agents. Proc Natl Acad Sci U S A. 1978;75(7):3327-3331.

64. Lee Hand W, Debra L Hand. Characteristics and mechanisms of azithromycin accumulation and efflux in human polymorphonuclear leukocytes. International Journal of Antimicrobial Agents. 2001;18:419-425.

65. Hand WL, King-Thompson NL, Holman JW. Entry of roxithromycin (RU 965), imipenem, cefotaxime, trimethoprim, and metronidazole into human polymorphonuclear leukocytes. Anitmicrob Agents Chemother. 1987;31(10):1553-1557.

66. Levitz SM, Harrison TS, Tabuni A, Liu X. Chloroquine induces human mononuclear phagocytes to inhibit and kill Cryptococcus neoformans by a mechanism independent of iron deprivation. $J$ Clin Invest. 1997;100(6):1640-1646.

67. Levitz SM1, Nong SH, Seetoo KF, Harrison TS, Speizer RA, Simons ER. Cryptococcus neoformans resides in an acidic phagolysosome of human macrophages. Infect Immun. 1999;672(2): 885-890.

68. Fox RI. Mechanism of action of hydroxychloroquine as an antirheumatic drug. Semin Arthritis Rheum. 1993;23(2 Suppl 1):82-91.

69. Geisow MJ, D’Arcy Hart P, Young MR. Temporal changes of lysosome and phagosome $\mathrm{pH}$ during phagolysosome formation in macrophages: studies by fluorescence spectroscopy. J Cell Biol. 1981;89(3):645-652.

70. Steinberg TH, Hand WL. Effect of phagocyte membrane stimulation on antibiotic uptake and intracellular bactericidal activity. Antimicrob Agents Chemother. 1987;31(4):660-662.

71. Leiper K, Morris AI, Rhodes JM. Open label trial of oral clarithromycin in active Crohn's disease. Aliment Pharmacol Ther. 2000;14(6): 801-806.

72. Flanagan PK, Campbell BJ, Rhodes JM. OC-140 Hydroxychloroquine as a treatment for crohn's disease: enhancing antibiotic efficacy and macrophage killing of E coli. Gut. 2012;61:A60-A61.

73. Oliphant CM, Green GM. Quinolones: a comprehensive review. Am Fam Physician. 2002;65(3):455-464.

74. Ilo CE, Ilondu NA, Okwoli N, et al. Effect of chloroquine on the bioavailability of ciprofloxacin in humans. Am J Ther. 2006;13(5): 432-435.

75. Vrančić M, Banjanac M, Nujić K, et al. Azithromycin distinctivelymodulates classical activation of human monocytes in vitro. $\mathrm{Br} \mathrm{J}$ Pharmacol. 2012;165(5):1348-1360. 
76. Munić V, Banjanac M, Koštrun S, et al. Intensity of macrolide anti-inflammatory activity in J774A. 1 cells positively correlates with cellular accumulation and phospholipidosis. Pharmacol Res. 2011;64(3):298-307.

77. Crosbie PA, Woodhead MA. Long-term macrolide therapy in chronic inflammatory airway diseases. Eur Respir J. 2009;33(1):171-181.

78. Anderson R, Jooné GK. In vitro investigation of the intraphagocytic bioactivities of ciprofloxacin and the new fluoroquinolone agents, clinafloxacin (CI-960) and PD 131628. Chemotherapy. 1993;39(6):424-431

79. Boya P, Andreau K, Poncet D, et al. Lysosomal membrane permeabilization induces cell death in a mitochondrion-dependent fashion. J Exp Med. 2003;197(10):1323-1334.

80. Kazzim OJ, Adegbolagun OM, Osho O, Anumudu CI. Additive effects of ciprofloxacin on the in-vitro activity of chloroquine against a clinical isolate of Plasmodium falciparum. Ann Trop Med Parasitol. 2006;100(7):579-584.

81. Abrantes P, Dimopoulos G, Grosso AR, do Rosário VE, Silveira H. Chloroquine mediated modulation of Anopheles gambiae gene expression. PLoS One. 2008;3(7):e2587.

82. Kanoh S, Rubin BK. Mechanisms of action and clinical application of macrolides as immunomodulatory medications. Clin Microbiol Rev. 2010;23(3):590-615.

83. Murata Y, Shimamura T, Hamuro J. The polarization of T(h)1/T(h)2 balance is dependent on the intracellular thiol redox status of macrophages due to the distinctive cytokine production. Int Immunol. 2002;14(2):201-212.

84. Elia AC, Prearo M, Pacini N, Dörr AJ, Abete MC. Effects of selenium diets on growth, accumulation and antioxidant response in juvenile carp. Ecotoxicol Environ Saf. 2011;74(2):166-173.

85. Cheeseman KH, Slater TF. An introduction to free radical biochemistry. Br Med Bull. 1993;49:481-493.

86. Wolin MS, Gupte SA, Oeckler RA. Superoxide in the vascular system. JVasc Res. 2002;39(3):191-207.

87. Muro S, Cui X, Gajewski C, Murciano JC, Muzykantov VR, Koval M. Slow intracellular trafficking of catalase nanoparticles targeted to ICAM-1 protects endothelial cells from oxidative stress. Am J Physiol Cell Physiol. 2003;285(5):C1339-C1347.

88. Iyawe HO, Onigbinde AO, Aina OO. Effect of chloroquine and ascorbic acid interaction on the oxidative stress status of Plasmodium berghei infested mice. Int J Pharmacol. 2006;2(1):1-4.

89. Sacre K, Criswell LA, McCune JM. Hydroxychloroquine is associated with impaired interferon-alpha and tumor necrosis factoralpha production by plasmacytoid dendritic cells in systemic lupus erythematosus. Arthritis Res Ther. 2012;14(3):R155.

90. Ouyang Q, Huang Z, Wang Z, Chen X, Ni J, Lin L. Effects of pristane alone or combined with chloroquine on macrophage activation, oxidative stress, and Th1/Th2 skewness. J Immunol Res. 2014;2014(2014):Article ID 613136.
91. Jeong JY, Jue DM. Chloroquine inhibits processing of tumor necrosis factor in lipopolysaccharide-stimulated RAW 264.7 macrophages. J Immunol. 1997;158(10):4901-4907.

92. Vazifeh D, Bryskier A, Labro MT. Effect of proinflammatory cytokines on theinterplay between roxithromycin, HMR 3647, or HMR 3004 and human polymorphonuclear neutrophils. Antimicrob Agents Chemother. 2000;44(3):511-521.

93. Kollias G, Douni E, Kassiotis G, Kontoyiannis D. The function of tumour necrosis factor and receptors in models of multi-organ inflammation, rheumatoid arthritis, multiple sclerosis and inflammatory bowel disease. Ann Rheum Dis. 1999;58(1):132-139.

94. Schulte W, Bernhagen J, Bucala R. Cytokines in sepsis: potent immunoregulators and potential therapeutic targets-an updated view. Mediators Inflamm. 2013;2013:165974.

95. Mosser DM, Zhang X. Activation of murine macrophages. Curr Protoc Immunol. 2008;14:14.2.

96. Furst DE. Pharmacokinetics of hydroxychloroquine and chloroquine during treatment of rheumatic diseases. Lupus. 1996;5 Suppl 1:S11-S15

97. Nujić K, Banjanac M, Munić V, Polančec D, Eraković Haber V. Impairment of lysosomal functions by azithromycin and chloroquine contributes to anti-inflammatory phenotype. Cellular Immunol. 2012;279(1):78-86.

98. Park YC, Pae HO, Yoo JC, Choi BM, Jue DM, Chung HT. Chloroquine inhibits inducible nitric oxide synthase expression in murine peritoneal macrophages. Pharmacol Toxicol. 1999;85(4):188-191.

99. Tamaoki J, Kondo M, Kohri K, Aoshiba K, Tagaya E, Nagai A. Macrolide antibiotics protect against immune complex-induced lung injury in rats: role of nitric oxide from alveolar macrophages. $J$ Immunol. 1999;163(5):2909-2915.

100. Rutz M, Metzger J, Gellert T, et al. Toll-like receptor 9 binds singlestranded CpG-DNA in a sequence- and pH-dependent manner. Eur $J$ Immunol. 2004;34(9):2541-2550.

101. Blasius AL, Beutler B. Intracellular toll-like receptors. Immunity. 2010;32(3):305-315

102. Kuznik A, Bencina M, Svajger U, Jeras M, Rozman B, Jerala R. Mechanism of endosomal TLR inhibition by antimalarial drugs and imidazoquinolines. J Immunol. 2011;186(8):4794-4804.

103. Wallace DJ, Gudsoorkar VS, Weisman MH, Venuturupalli SR. New insights into mechanisms of therapeutic effects of antimalarial agents in SLE. Nat Rev Rheumatol. 2012;8(9):522-533
Journal of Inflammation Research

\section{Publish your work in this journal}

The Journal of Inflammation Research is an international, peer-reviewed open-access journal that welcomes laboratory and clinical findings on the molecular basis, cell biology and pharmacology of inflammation including original research, reviews, symposium reports, hypothesis formation and commentaries on: acute/chronic inflammation; mediators of inflamma-

\section{Dovepress}

tion; cellular processes; molecular mechanisms; pharmacology and novel anti-inflammatory drugs; clinical conditions involving inflammation. The manuscript management system is completely online and includes a very quick and fair peer-review system. Visit http://www.dovepress.com/ testimonials.php to read real quotes from published authors. 